\title{
Exploring the potential of reformed-exhaust gas recirculation (R-EGR) for increased efficiency of methanol fueled SI engines
}

\author{
Duc-Khanh Nguyen, Louis Sileghem, Sebastian Verhelst \\ Department of Flow, Heat and Combustion Mechanics, Ghent University \\ Sint-Pietersnieuwstraat 41, B-9000 Ghent, Belgium
}

\begin{abstract}
Methanol is a promising fuel for spark ignition engines because of its high octane number, high octane sensitivity, high heat of vaporization and high laminar flame speed. To further boost the efficiency of methanol engines, the use of waste heat for driving fuel reforming was considered. This study explores the possibility of the reformed-exhaust gas recirculation (R-EGR) concept for increased efficiency of methanol engines. A simple Otto cycle calculation and a more detailed gas dynamic engine simulation are used to evaluate that potential. Both methodologies point to an enhancement in engine efficiency with fuel reforming compared to conventional EGR but not as much as the increase in lower heating value of the reforming product would suggest. A gas dynamic engine simulation shows a shortening of the flame development period and the combustion duration in line with the expected behavior with the hydrogen-rich reformer product gas. However, the heat loss increases with the presence of hydrogen in the reactants. The improvement of brake thermal efficiency is mainly attributed to the reduction of pumping work. The R-EGR concept is also evaluated for ethanol and iso-octane. As the reforming fraction increases, the efficiency of ethanol and iso-octane fueled engines rises faster than for the methanol engines due to a higher enhancement of exergy in their reforming products. At high re-
\end{abstract}

\footnotetext{
* Corresponding author

Email address: duckhanh.nguyen@ugent. be (Duc-Khanh Nguyen)
}

Preprint submitted to Fuel

September 15, 2018 
forming fractions, the efficiency of the ethanol engine becomes higher than with methanol. However, if the impact of optimal compression ratio for different fuels are considered, the methanol engine is able to produce a higher efficiency than the ethanol engine.

Keywords: methanol, reformed-exhaust gas recirculation (R-EGR), diluted combustion, fuel effects, molar expansion ratio

\title{
Nomenclature
}

\author{
Abbreviations \\ aBDC after bottom dead center \\ $\mathrm{Al}_{2} \mathrm{O}_{3}$ aluminum oxide \\ aTDC after non-firing top dead center \\ $\mathrm{aTDC}_{\mathrm{f}}$ after firing top dead center \\ bBDC before bottom dead center \\ BMEP brake mean effective pressure \\ bTDC before non-firing top dead center \\ $\mathrm{bTDC}_{\mathrm{f}}$ before firing top dead center \\ BTE brake thermal efficiency \\ CA crank angle \\ CAD crank angle degree \\ $\mathrm{CH}_{3} \mathrm{OH}$ methanol \\ $\mathrm{CH}_{4}$ methane \\ CO carbon monoxide \\ $\mathrm{CO}_{2}$ carbon dioxide
}




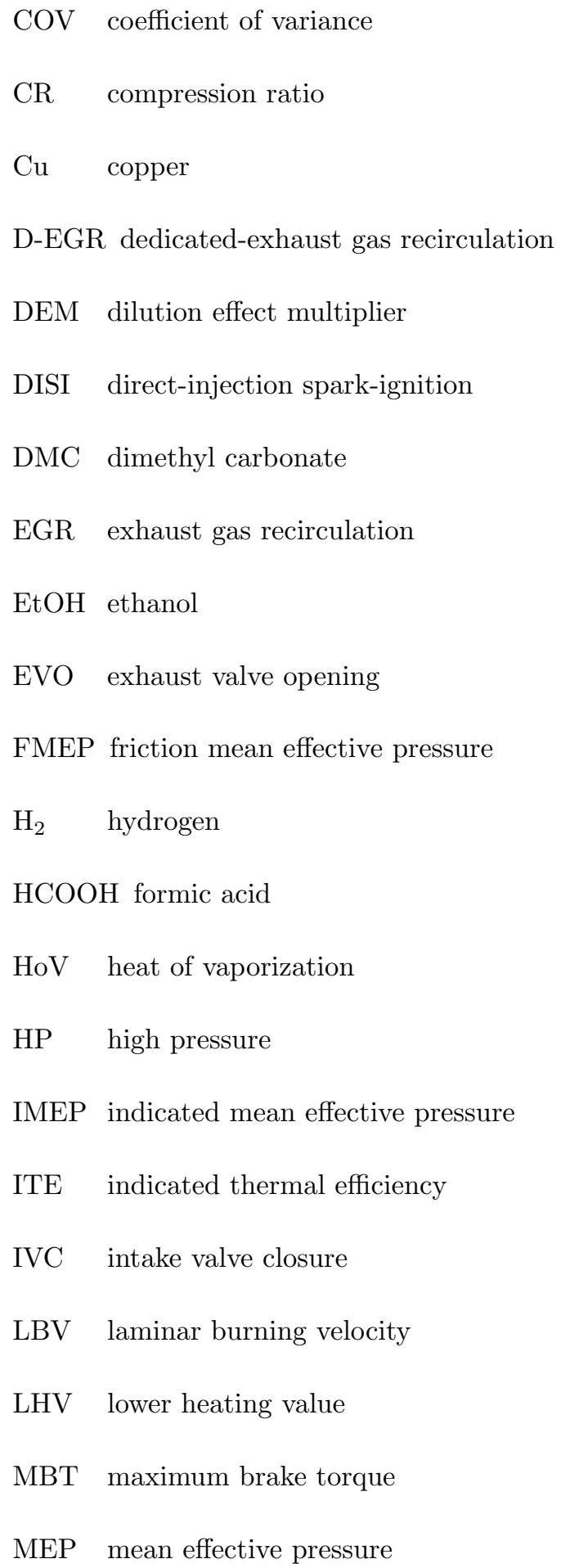




\author{
MER molar-expansion ratio \\ MF methyl formate \\ Mn manganese \\ $\mathrm{N}_{2} \quad$ nitrogen \\ $\mathrm{O}_{2} \quad$ oxygen \\ PMEP pumping mean effective pressure \\ R-EGR reformed-exhaust gas recirculation \\ $\mathrm{Rh} \quad$ rhodium \\ RON research octane number \\ SI spark ignition \\ Symbols \\ $\Delta \mathrm{h} \quad$ enthalpy of formation \\ $\gamma \quad$ specific heat ratio \\ $\lambda \quad$ excess air fuel ratio \\ $u^{\prime} \quad$ turbulent intensity
}

\title{
1. Introduction
}

Increasing brake thermal efficiency (BTE) of spark ignition (SI) engines currently is a strict requirement for engine manufacturers to meet the future $\mathrm{CO}_{2}$ emission legislation. Several technologies have been investigated and applied 5 to increase the engine efficiency such as cylinder deactivation, variable compression ratio, exhaust gas recirculation (EGR), Miller/Atkinson cycle, water injection, etc. 1]. Together with the development of engine technologies, fuel properties play an important role for the potential engine efficiency [2, 3]. Due 
to the limitation of fossil fuels and the requirement of a sustainable mobility, fuels synthesized using renewable energy sources (or electro-fuels, e-fuels) could play a key role [4. The e-fuel properties can be optimized to increase engine efficiency and reduce raw emissions [5]. The fuel should have a high research octane number (RON), high octane sensitivity, high heat of vaporization $(\mathrm{HoV})$, and high laminar burning velocity $(\mathrm{LBV})$ 6]. Methanol $\left(\mathrm{CH}_{3} \mathrm{OH}\right)$ is the simplest type of liquid synthetic fuel [7, and therefore has production advantages compared to more complex fuels. There is no C-C bond in the chemical formula enabling an almost soot-free combustion. Compared to other soot-free e-fuel candidates such as dimethyl carbonate (DMC) and methyl formate (MF) [ $[$, methanol has a higher energy density, higher HoV and faster LBV [9, 10]. The RON of methanol is comparable to DMC, and lower than MF (RON of 115), however, the octane sensitivity of methanol is the highest (20 for methanol versus 7 for DMC, and 0.2 for MF). Based on these considerations, methanol seems to be a very promising synthetic fuel for future SI engines in term of production, energy density as well as combustion.

The potential of methanol for increased efficiency and reduced exhaust emissions has been reported in previous researches [11, 12, 13. A higher compression ratio $(\mathrm{CR})$ engine can be used to fully utilize the anti-knock properties of the fuel, and the engine can be further downsized compared to gasoline engines [14]. In order to further boost the fuel economy, a waste heat recovery system can so be used. The engine exhaust heat can be employed to reform methanol at low temperature using a cheap catalyst [15]. Methanol can dissociate to a $\mathrm{H}_{2} / \mathrm{CO}$ blend (methanol thermal decomposition, reaction $\mathrm{R} 1$ ) or react with $\mathrm{H}_{2} \mathrm{O}$ to produce a $\mathrm{H}_{2} / \mathrm{CO}_{2}$ mixture (methanol steam reforming, reaction $\mathrm{R} 2$ ). As both are endothermic reactions, the lower heating value (LHV) of decomposed methanol 35 (in R1) and methanol steam reforming product (in R2) increases by $20 \%$ and $13 \%$ against methanol, respectively.

$$
\begin{aligned}
& \mathrm{CH}_{3} \mathrm{OH} \stackrel{\text { catalyst }}{\longrightarrow} \mathrm{CO}+2 \mathrm{H}_{2} \quad \Delta \mathrm{h}=+91(\mathrm{~kJ} / \mathrm{mol}) \\
& \mathrm{CH}_{3} \mathrm{OH}+\mathrm{H}_{2} \mathrm{O} \stackrel{\text { catalyst }}{\longrightarrow} \mathrm{CO}_{2}+3 \mathrm{H}_{2} \quad \Delta \mathrm{h}=+49(\mathrm{~kJ} / \mathrm{mol})
\end{aligned}
$$

During the 1980s, several tests with dissociated/decomposed methanol on 
SI engines were performed and a large relative improvement in engine efficiency versus gasoline was found [16, 17, 18]. However, the enhancement was small (3$7 \%$ ) if it was compared to the efficiency that could be obtained with an engine operated on pure methanol, which itself is smaller than the change in LHV of dissociated methanol [19]. Work was also done on decomposed methanol at lean 45 conditions, and showed a significant improvement in efficiency compared to neat methanol [20, 21].

Recently, Poran et al. have built the first prototype of a direct-injection SI engine with a high-pressure thermal recuperation [22]. Methanol is converted to syngas at high pressure through steam reforming. The product is injected directly in the combustion chamber, allowing the volumetric efficiency of the engine to be maintained. The occurrence of back-fire and pre-ignition can also easily be solved then. The experiments with methanol reformate from the reformer [22] and from the compressed gas bottles [23, 24, 25] both showed a significant improvement in efficiency (18-39\%) and lower emissions (up to $94 \%$ in $\mathrm{NO}_{\mathrm{x}}, 96 \%$ in $\mathrm{CO}, 97 \%$ in $\mathrm{HC}$, and $25 \%$ in $\mathrm{CO}_{2}$ ) compared to gasoline.

These above mentioned studies employed methanol reformate as the fuel for SI engines, i.e. $100 \%$ fuel was reformed. A part of the fuel also can be reformed to support the combustion of liquid fuels. The fuel can be reformed through in-cylinder reforming or through catalytic reforming. In the former case, the ${ }_{60}$ cylinder works as a reactor for partial oxidation to produce syngas [26, 27]. The dedicated-exhaust gas recirculation (D-EGR) engine concept has been built [28] based on that principle. One (of four) cylinder operates with a rich mixture, the exhaust gas of that cylinder returns back to the intake to mix with the intake air. The EGR ratio is almost fixed at $25 \%$, and the engine can be operated at a higher CR. Because of the rich combustion in the dedicated cylinder, the combustion produces $\mathrm{H}_{2}$ and $\mathrm{CO}$. The amount of $\mathrm{H}_{2}$ and $\mathrm{CO}$ strongly depends on the enrichment in the dedicated cylinder. Richer combustion generates a higher concentration of $\mathrm{H}_{2}$ and $\mathrm{CO}$, which supports the combustion in the other cylinders. Shorter combustion duration was observed, leading to a reduction in 70 fuel consumption. The rich limit of methanol combustion is higher than gasoline, 
causing the dedicated cylinder to be able to operate at an equivalence ratio of 2.67 (versus 1.6 for gasoline) [29], so more hydrogen can be produced. The brake thermal efficiency of the D-EGR engine with methanol improves by 1-3\% compared to gasoline.

For the catalytic reforming, the catalyst is heated up by contacting directly with the hot gas or through a heat exchanger. The direct contact is preferred because it provides a better heat transfer and the combustion products can be used as an additional reactant. The hot gas is the EGR mixture (reformedEGR concept) [30, or is the exhaust of one cylinder [31, 32]. In the first one, the fuel is injected into the EGR loop, upstream the catalyst and reacted with water vapor and/or $\mathrm{CO}_{2}$ in the exhaust over the catalyst to produce syngas (see Figure 11. The reforming products and the inert gases then recirculate back to the intake to mix with the fresh air. This concept has been investigated in both spark ignition and compression ignition engines. For the SI engines, the R-EGR concept was studied with bioethanol and gasoline [30, 33, 34, 35, 36. Similar work was done by Ashida et al. 37, the EGR tolerance limit can be extended with the hydrogen contained in the reformate. However, the catalyst is quickly deactivated due to sulfur adsorption. The second idea is the use of one of four cylinders to produce a lean combustion product. The additional fuel injects at 90 the end of the expansion stroke, to provide a fuel rich mixture (with oxygen left from the combustion) and feed it into the catalyst during the exhaust stroke. The fuel reacts with lean combustion products $\left(\mathrm{O}_{2}, \mathrm{H}_{2} \mathrm{O}\right.$ and $\left.\mathrm{CO}_{2}\right)$ over a $2 \%$ wt $\mathrm{Rh}$ on $\mathrm{Al}_{2} \mathrm{O}_{3}$ catalyst [31] which is located inside the exhaust system of that cylinder. The products then recirculate back to the intake to mix with the air of the other cylinders. For a given engine load and speed, the catalytic EGR-loop can stabilize the combustion with a volumetric equivalent of 45-55\% EGR, and the fuel consumption was shown to decrease by $8 \%$ compared to the baseline case [32].

To the authors' knowledge, no investigation on the reformed-EGR (or REGR) concept with methanol was published before. The current paper aims to explore the potential of this concept for increased efficiency of methanol en- 


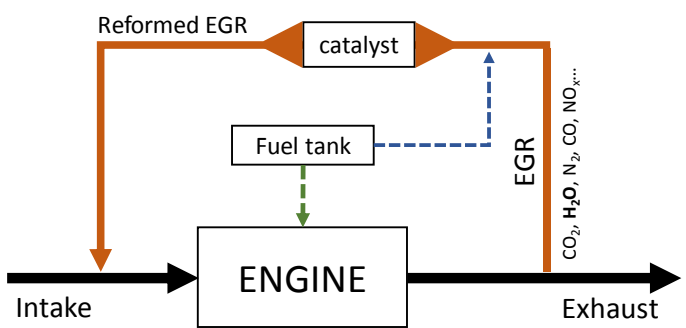

Figure 1: The reformed-exhaust gas recirculation (R-EGR) concept.

gines. The impact of the reforming fraction and the EGR ratio on the efficiency needs to be studied. The change of heat transfer, pumping work, friction work, combustion, and so on in this concept is still unknown. An Otto cycle efficiency and a full engine simulation using GT-Power are employed to estimate these changes. Finally, we also present some calculations for ethanol and iso-octane to evaluate the fuel effect on the potential of the R-EGR concept.

\section{Otto cycle efficiency}

\subsection{Methodology}

\subsubsection{Theoretical efficiency}

The R-EGR concept is complex, thus it requires a significant effort to predict the system efficiency. In a first step, we used the simplification of an Otto cycle as an approximation, to get an initial idea of the impact of fuel reforming on engine efficiency. This efficiency is computed using the extracted work and the fuel energy, similar to the methodology of Szybist et al. 3. Figure 2 shows the pressure-volume diagram of the Otto cycle. The surface enclosed by the graph is used to calculate the Otto mean effective pressure (Otto MEP). The Otto cycle was calculated with the initial pressure $\mathrm{P}_{0}$ of 1 bar, and the initial temperature $\mathrm{T}_{0}$ of $343 \mathrm{~K}$. The compression ratio $(\mathrm{CR})$ and the expansion ratio was 9:1. That $\mathrm{CR}$ is lower than the geometric CR of current production SI engines; however, with a late intake valve closure (IVC) as used in a number of high-efficiency concepts, the effective compression ratio is comparable to 9:1. 
In practice, fuel evaporates during the intake and the compression strokes, with the evaporation rate being strongly dependent on the in-cylinder condition. For a simplification of this calculation, the influence of heat of vaporization (HoV) was ignored. The liquid fuel was assumed to be fully vaporized at a constant temperature before compression. A difference in the specific heat ratio $(\gamma)$ causes a change in the post-compression state $\left(\mathrm{P}_{1}\right.$ and $\left.\mathrm{T}_{1}\right)$. The $\gamma$ for the compression and the expansion processes was calculated at $800 \mathrm{~K}$ and 2000 $\mathrm{K}$, respectively. Variation in the $\gamma$ during the compression and expansion was neglected. After an isochoric combustion, the pressure and the temperature rise to $\mathrm{P}_{2}$ and $\mathrm{T}_{2}$. The reactant is burned stoichiometrically, completed combustion products include carbon dioxide $\mathrm{CO}_{2}$, water vapor $\mathrm{H}_{2} \mathrm{O}$, and nitrogen $\mathrm{N}_{2}$. The dissociation of completed combustion products at high temperatures to produce $\mathrm{CO}$ and $\mathrm{H}_{2}[3$ was ignored. The combustion product then expands to a lower pressure and temperature, $\mathrm{P}_{3}$ and $\mathrm{T}_{3}$. The cycle work can be then calculated.

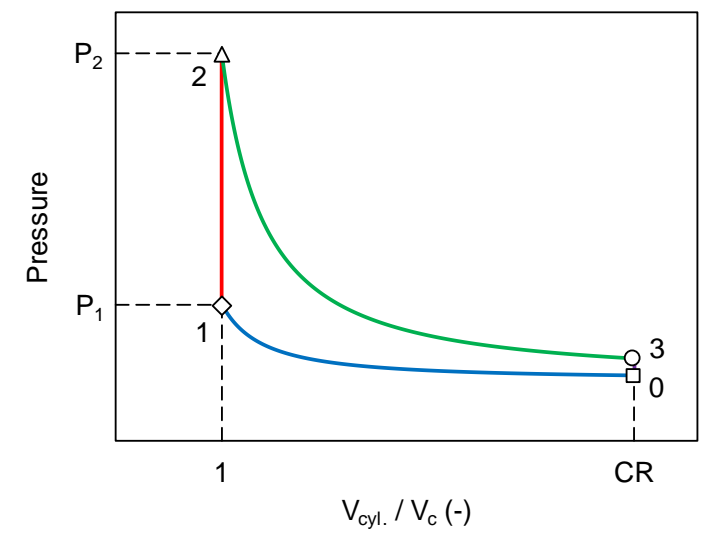

Figure 2: The pressure-volume diagram of the Otto cycle.

In the R-EGR cases, a portion of fuel injects into the EGR loop. The fuel can react with water vapor (steam reforming) or with carbon dioxide (dry reforming) or split (thermal decomposition) to produce $\mathrm{H}_{2}$-rich gas. The required energy for thermal decomposition and especially for dry reforming are much higher than for steam reforming. Therefore, the reforming follows reaction $\mathrm{R} 2$ which has a 
minimum-energy barrier to produce $\mathrm{H}_{2}$ and $\mathrm{CO}_{2}$. The combustion reaction can be written as below

$$
\begin{aligned}
& \mathrm{CH}_{3} \mathrm{OH}+\mathrm{x}\left(\mathrm{O}_{2}+3.76 \mathrm{~N}_{2}\right)+\mathrm{Y}_{\text {res }}\left(\mathrm{aCO}_{2}+\mathrm{bH}_{2} \mathrm{O}+\mathrm{cN}_{2}\right)+\cdots \\
& \mathrm{Y}_{\text {egr }}\left(\mathrm{aCO}_{2}+\mathrm{bH}_{2} \mathrm{O}+\mathrm{cN}_{2}\right)-\mathrm{X}_{\text {fuel }} \mathrm{H}_{2} \mathrm{O}+\mathrm{X}_{\text {fuel }} \mathrm{CO}_{2}+3 \mathrm{X}_{\text {fuel }} \mathrm{H}_{2} \\
& \longrightarrow \mathrm{aCO}_{2}+\mathrm{bH}_{2} \mathrm{O}+\mathrm{cN}_{2}
\end{aligned}
$$

where $Y_{\text {res }}$ is the residual mass fraction in the combustion chamber (internal EGR), $\mathrm{Y}_{\text {egr }}$ is the EGR mass fraction, and $\mathrm{X}_{\text {fuel }}$ is the normalized amount of reformed fuel to the unconverted fuel. Coefficients $\mathrm{a}, \mathrm{b}, \mathrm{c}$ and $\mathrm{x}$ were calculated as a function of $Y_{\text {res }}, Y_{\text {egr }}$ and $X_{\text {fuel }}$ to balance the reaction. The number of moles in reaction $\mathrm{R} 3$ was normalized to one mole of $\mathrm{CH}_{3} \mathrm{OH}$. $\mathrm{X}_{\text {fuel }}$ mole of methanol was injected to the catalyst, it consumed $\mathrm{X}_{\text {fuel }}$ mole water, produced $\mathrm{X}_{\text {fuel }}$ mole $\mathrm{CO}_{2}$ and $3 \mathrm{X}_{\text {fuel }}$ mole $\mathrm{H}_{2}$. The reforming fraction (fraction of the reformed fuel to the total fuel) can be calculated as below

$$
Y_{\text {reforming }}=\frac{X_{\text {fuel }}}{1+X_{\text {fuel }}} * 100(\%)
$$

In this study, $\mathrm{Y}_{\text {res }}$ was set at 0.04 (4\% mass), $\mathrm{Y}_{\text {egr }}$ ranged from 0 to 0.5 (no EGR to EGR $50 \%$ by mass, with steps of $10 \%$ ), and $\mathrm{X}_{\text {fuel }}$ varied from 0 to 1 (no reforming to reforming fraction of 50\%). The purpose of fuel reforming is supporting the combustion of liquid fuel, so the fuel fraction for the reforming is less or equal to the fuel injected directly in the combustion chamber. The reforming started at EGR ratio $\geqslant 20 \%$, which is when the water vapor in the EGR loop is sufficient for the steam reforming.

\subsubsection{Analysis of energy losses}

In the previous section, the idealized Otto cycle was employed. That cycle does not take the effect of combustion duration, heat transfer, and friction into account. In this part, these idealizations were removed one-by-one to estimate their effect on the efficiency. Some engine parameters are needed to calculate these impacts. The specifications of a production engine, a Volvo T3, was employed. More information about the engine can be found in the next section. At the standard valve timing, the effective compression ratio and the effective 


$$
Q=A h\left(T_{g a s}-T_{w a l l}\right)
$$

where $A$ is the heat transfer area, $h$ is the heat transfer coefficient, $T_{\text {gas }}$ is 


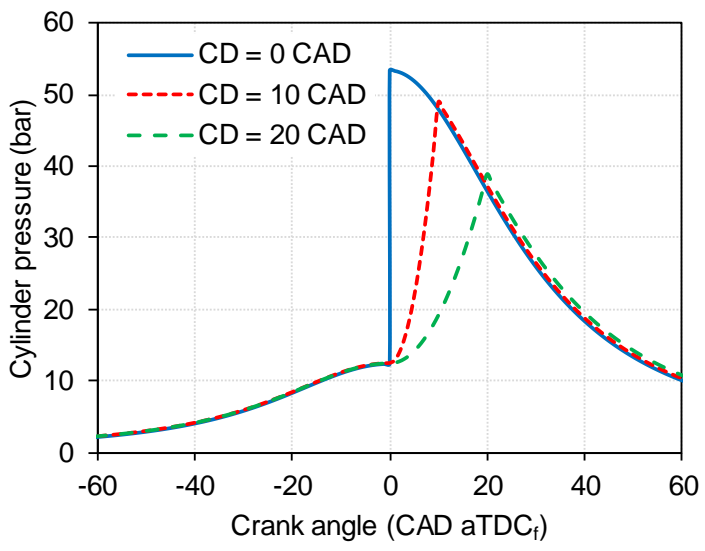

(a) Pressure-degree crank angle diagram

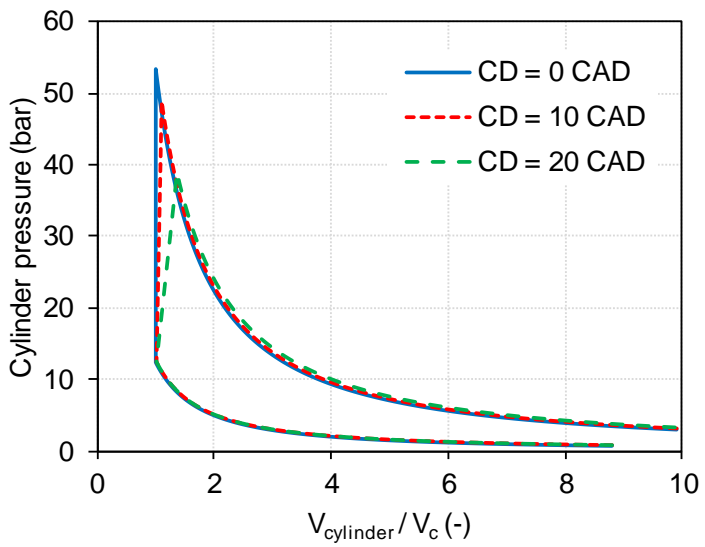

(b) Pressure-compression ratio diagram

Figure 3: Impacts of combustion duration on the in-cylinder pressure. 
the in-cylinder gas temperature, and $T_{\text {wall }}$ is the wall temperature. The heat transfer coefficient from Hohenberg's model was employed [38]. Therefore, the heat transfer is related as follows

$$
Q \sim A P^{0.8} T_{\text {gas }}^{-0.4} V^{-0.06}\left(T_{\text {gas }}-T_{\text {wall }}\right)
$$

where $P$ is the cylinder pressure, $V$ is volume of the combustion chamber. The wall temperature was calculated based on the Otto MEP [39], so the calculated $T_{\text {wall }}$ is higher than the real wall temperature. Based on equation 3 , the relative change of $Q$ against the baseline case $\left(\mathrm{P}_{0}\right.$ of 0.6 bar, combustion duration of $0 \mathrm{CAD}$, no EGR, and no reforming) can be calculated. In the baseline case, the relative heat transfer was assumed to be $15 \%$ of the total fuel energy [40. Therefore, the heat loss in another cases can be estimated.

For simplification, the relative change of $Q$ is based on the relative change of $Q_{\max }$. The heat transfer rate reaches its peak at the end of combustion, i.e. $Q_{\max }$ occurs at 0,10 , and $20 \mathrm{CAD}$ aTDC $\mathrm{f}$. Because the combustion efficiency equals $100 \%$, the burned gas temperatures at these crank angles $\left(\mathrm{T}_{2}\right)$ were used for the calculation. The piston and cylinder head were assumed to be flat (pancake combustion chamber) to calculate $A$ and $V$ in equation 3 . With a longer combustion duration, $A$ and $V$ increase, while $P$ and $T_{\text {gas }}$ decrease. A test matrix was computed for the conventional EGR case, varying $\mathrm{P}_{0}$ (from 0.6 bar to 1.4 bar, steps of 0.2 bar), combustion duration (from $0 \mathrm{CAD}$ to $20 \mathrm{CAD}$, steps of $10 \mathrm{CAD}$ ), and EGR ratio (no EGR, EGR ratio of 20, 30 and 40\%). For the R-EGR case, the reforming fraction was fixed at 20\%, and the EGR ratio ranged from $20 \%$ to $40 \%$ with steps of $10 \%$. Therefore, there are $5 \times 3 \times 4=60$ data points for the EGR cases (including the baseline) and $5 \times 3 \times 3=45$ data points for the R-EGR cases. The relative heat transfer and Otto MEP were calculated for the resulting 105 points, and the relationship between these parameters was plotted in Figure 4. As can be seen, the R-EGR case has higher heat loss due to the increase in the post-combustion temperature. The absolute heat transfer 225 increases; however, the relative HT decreases as load increases [41. 


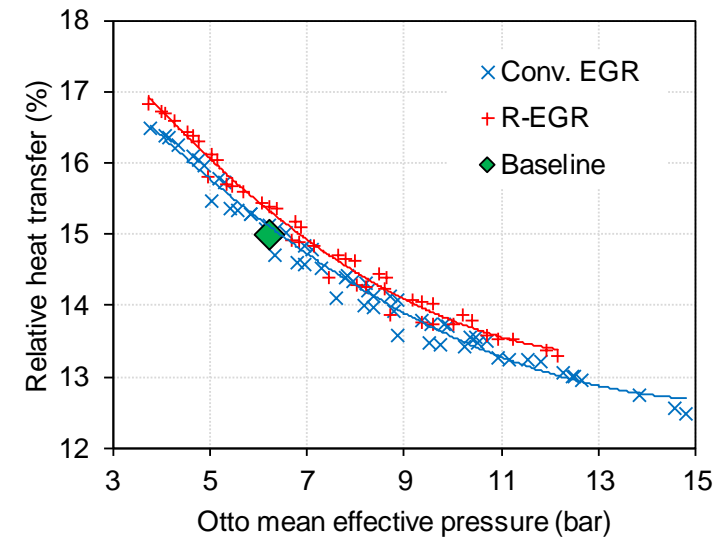

Figure 4: The relative heat transfer as a function of the Otto MEP.

The impact of friction was estimated by evaluating the friction mean effective pressure (FMEP) followed the Chen-Flynn expression [42, which is described as a function of mean piston speed $U_{p}($ in $\mathrm{m} / \mathrm{s})$ and peak cylinder pressure $P_{\max }$ (in bar):

$$
F M E P=0.4+0.005 P_{\max }+0.09 U_{p}+0.0009 U_{p}^{2}
$$

Engine speed is set at $1500 \mathrm{rpm}$, giving a mean piston speed of $4.07 \mathrm{~m} / \mathrm{s}$. The $P_{\max }$ from the Otto cycle was used; therefore, the calculated FMEP is higher than in practice. FMEP decreases as the combustion duration increases. The last key loss is the pumping work. In the Otto cycle, the pumping mean effective pressure (PMEP) equals the difference in the intake and exhaust pressures. Due to the lack of the exhaust pressure, the impact of PMEP is ignored, thus the gross BTE will be used to present the efficiency of the engine.

\subsection{Results}

\subsubsection{Idealized efficiency}

Figure 5 presents the post-combustion pressure versus post-combustion temperature for different EGR ratios and different reforming fractions. The upper line shows the relationship between $\mathrm{P}_{2}$ and $\mathrm{T}_{2}$ of conventional EGR. At high 
EGR levels, a significant decline in $\mathrm{P}_{2}$ and $\mathrm{T}_{2}$ can be seen. Due to the replacement of the burned gases, amount of air and fuel decrease because of the maintained initial pressure. The reactants have less energy than the non-EGR case, leading to a reduction in $\mathrm{P}_{2}$ and $\mathrm{T}_{2}$. Three lines for reforming fractions of $13 \%, 33 \%$ and $50 \%$ are also plotted in this figure. Compared to the conventional EGR, the R-EGR cases have a lower pressure and a higher temperature. The reactant energy rises with the fuel reforming, this explains for a growth in the combustion temperature. Whereas, a reduction in molar-expansion ratio (MER) of reformate results in a decline of the post-combustion pressure. The MER is defined as the ratio of product moles to reactant moles [3]. In a constant volume combustion chamber, if the heat release is neglected, the postcombustion pressure equals MER (in bar) if the initial pressure is 1 bar. Thus the fuel which has MER greater than unity is able to produce more work. MER of hydrogen is around 0.85 , much lower than methanol, $\sim 1.06[3]$, therefore the combustion of hydrogen produces a lower work than is indicated by its LHV. As reforming fraction increases, pressure decreases and temperature enhances.

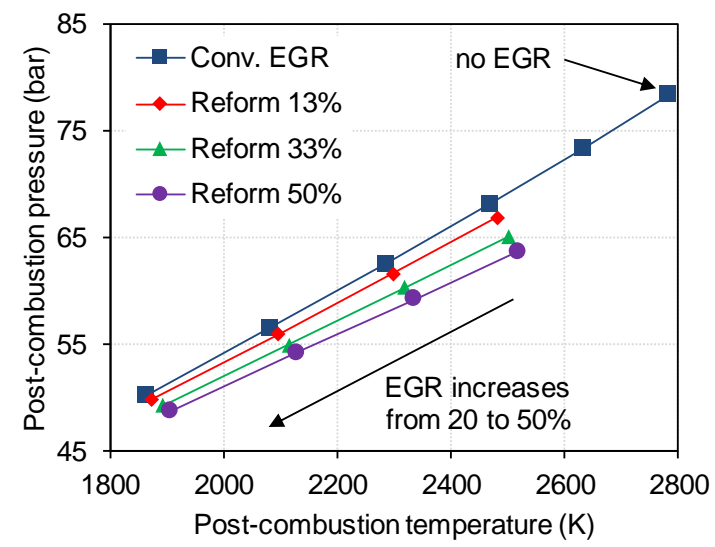

Figure 5: Post-combustion pressure and temperature at different EGR ratios and different reforming fractions.

The lower post-combustion pressure points to the cycle work of the R-EGR cases potentially being lower than with conventional EGR. This is confirmed in 

the pumping work of the non-EGR case would be high, so a bigger improvement in BTE with the R-EGR concept might be seen.

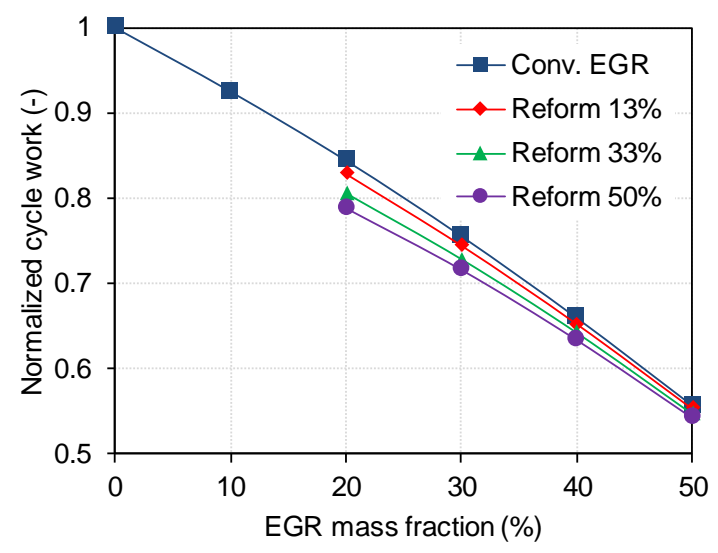

Figure 6: Normalized cycle work at different reforming fractions versus EGR ratio.

Figure 7 illustrates the Otto cycle efficiency, plotted as a function of the reforming fraction. It can be seen that the efficiency improves significantly with the rise of EGR ratio (at reforming fraction of 0\%). Although the cycle work decreases (Figure 6), a significant reduction in inlet energy due to the displacement effect of the burned gases is the main reason for that efficiency 
improvement. The influence of the reforming fraction is presented at EGR ratio

280 slightly compared to the conventional EGR. It can be explained by a small enhancement in exergy of the methanol steam reforming product compared to methanol [43. The LHV has to compensate for the reduction of MER, thus the increase in efficiency is not as high as the increase in the LHV. At higher EGR ratios, the increase is more obvious.

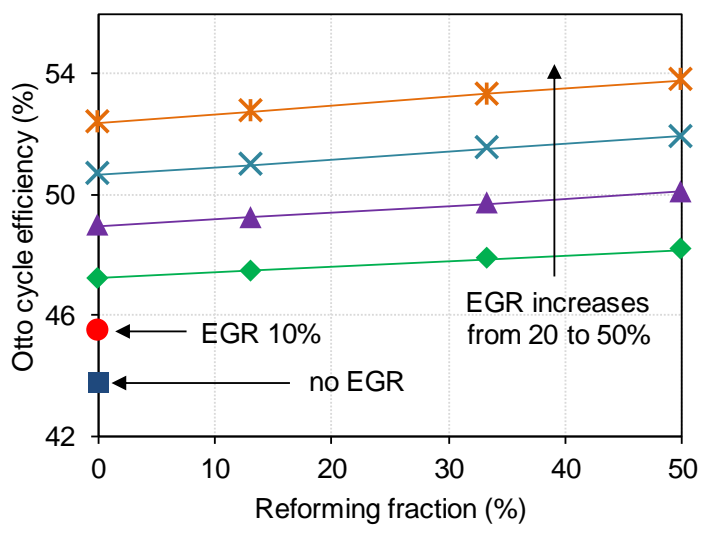

Figure 7: Influence of reforming fraction on the Otto cycle efficiency at different EGR ratios.

Figure 8 demonstrates the relationship between the Otto cycle efficiency and the MER. In the case of conventional EGR (square symbols), the MER decreases as the dilution level rises. This is due to the MER of the combustion products being 1, lower than methanol. Different reforming fractions (13\%, 33\% and 50\%) are also plotted in this Figure. In the cases of reformed fractions $33 \%$ (triangular symbols) and 50\% (circular symbols), the MER increases thanks to the dilution. $\mathrm{H}_{2}$ has a MER less than unity $(\sim 0.85)$, thus a mixture with high $\mathrm{H}_{2}$ concentration has MER less than 1. Therefore, the MER in the cases of reformed fraction of $33 \%$ and $50 \%$ increases as EGR ratio increases.

A smaller change in MER with fuel reforming can be seen at high EGR ratios. For example, the MER decreases from 1.046 to 0.958 at EGR ratio of $20 \%$ and from 1.027 to 0.974 at EGR ratio of $50 \%$. This explains for a visible 
improvement in the Otto cycle efficiency at 50\% EGR (see Figure 7). There is a strong correlation between the Otto cycle efficiency and the MER at a certain reforming fraction. The MER approaches unity with increasing EGR ratio (see the linear trend lines for different reforming fractions). At MER of 1 (EGR ratio of $100 \%$ ), the end of each trend line shows the theoretical efficiency that can be achieved with a certain reforming fraction. The absolute difference in the efficiency between reforming $50 \%$ and conventional EGR cases is $\sim 3 \%$. In practice, the engine is obviously not able to operate at that EGR ratio, meaning the improvement in engine efficiency with the R-EGR concept is limited. The change in the MER explained for a small improvement in engine efficiency with the dissociated methanol compared to the neat methanol at $\lambda$ close to 1 [19]. A bigger difference in the efficiency can be seen at a highly diluted condition (lean burn or EGR dilution), as in [20, 21].

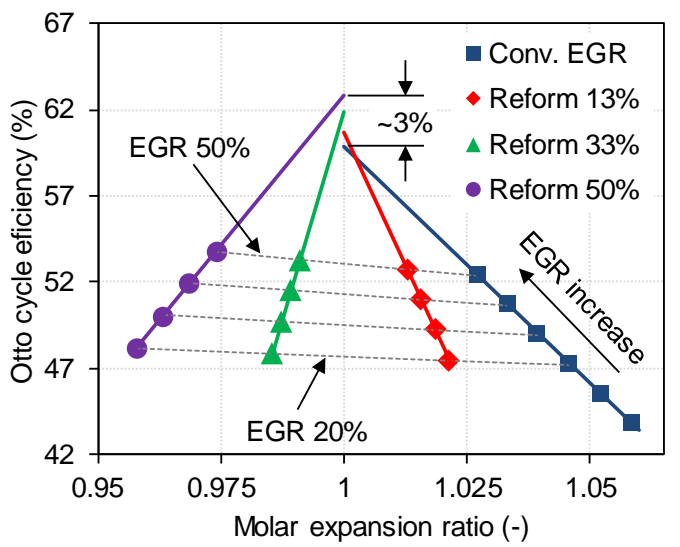

Figure 8: The relationship between molar expansion ratio and the Otto cycle efficiency.

The Otto cycle efficiency calculation indicated the efficiency to rise only very slightly very limited with fuel reforming at equal EGR fractions due to the limited change in exergy of the reformate. A bigger increase could come from enhanced EGR tolerance due to an improved combustion stability of the reformed products which will be investigated in the last section. The Otto cycle however only considers the thermodynamic part, another impacts such as heat 
transfer, pumping work, friction work, combustion duration, etc. are not taken into account. A simple estimation of these losses was done and the results will be presented in the following section.

\subsubsection{Impact of energy losses}

Figure 9 shows the efficiency losses as functions of EGR ratio. The uppermost solid line represents the Otto cycle efficiency, without heat losses (adiabatic case). The efficiency increases as EGR ratio improves. Lower efficiency lines are resulted by adding losses such as combustion duration (20 CAD duration), heat transfer, and friction losses. The second line shows the Otto efficiency with combustion duration of $20 \mathrm{CAD}$. The third line presents the gross indicated thermal efficiency (ITE), i.e. accounting for heat losses, with the same combustion duration as in the second line. The pumping loss is neglected, so the most bottom line, which includes frictional losses, represents the gross BTE curve. 330 The results of R-EGR cases with the reforming fraction of $20 \%$ are also added in this Figure (dashed lines with symbols), with EGR ratio ranges from 20 to $40 \%$. Figure 9a illustrates the efficiency with a constant initial pressure, $\mathrm{P}_{0}$ of 1 bar. After increasing the combustion duration from 0 CAD to $20 \mathrm{CAD}$, the absolute efficiency drops by $\sim 3-5 \%$. If the heat loss is taken into account, the efficiency significantly decreases to the gross ITE. Before adding the heat loss, the efficiency of the R-EGR case is a bit higher than the conventional EGR. However, there is almost no difference in the gross ITE between two cases. The improvement in the Otto cycle efficiency is transferred to the heat loss. After adding the friction loss, the efficiency in the R-EGR cases are slightly lower than the conventional EGR because of the increase in the relative friction loss. Although the post-combustion pressure declines in R-EGR case (Figure 5), the relative friction loss improves because of a reduction in inlet energy. In both cases, the relative friction energy increases as EGR ratio increases.

Figure $9 \mathrm{~b}$ shows the efficiency losses at a constant gross BMEP of 5 bar.

345 The initial pressure is now controlled to maintain the gross BMEP of 5 bar for different EGR ratio and combustion duration. The peak pressure $\left(\mathrm{P}_{1}\right)$ increases 


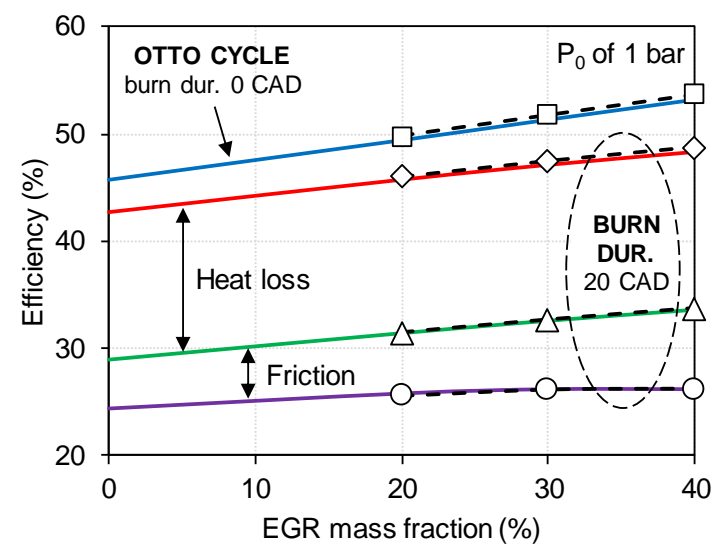

(a) Key efficiency losses at $\mathrm{P}_{0}$ of 1 bar

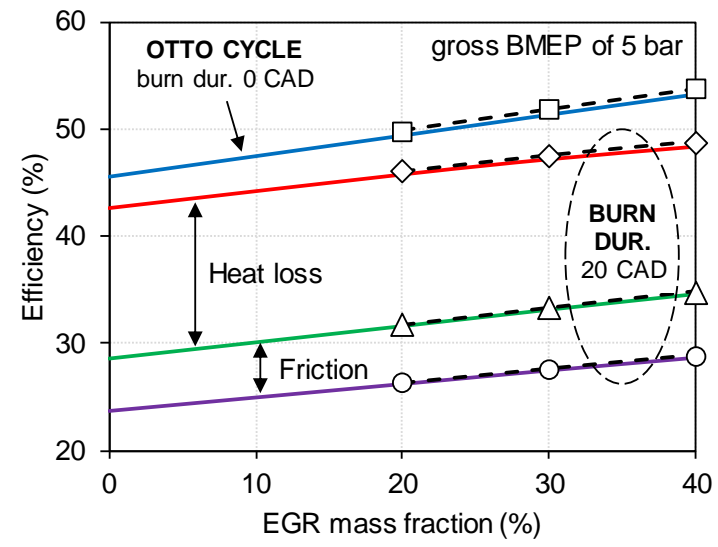

(b) Key efficiency losses at gross BMEP of 5 bar

Figure 9: Key efficiency losses as a function of EGR ratio. Solid lines: conventional EGR, dashed lines with symbols: R-EGR with reforming fraction of $20 \%$. 
and the maximum temperature $\left(\mathrm{T}_{1}\right)$ decreases as EGR ratio increases. In the conventional EGR cases (combustion duration of $20 \mathrm{CAD}$ ), the relative heat transfer slightly decreases when the EGR ratio increases from $20 \%$ to $40 \%$. concept. However, they are not able to predict the real efficiency. A more complete picture can be obtained by using a gas-dynamic 


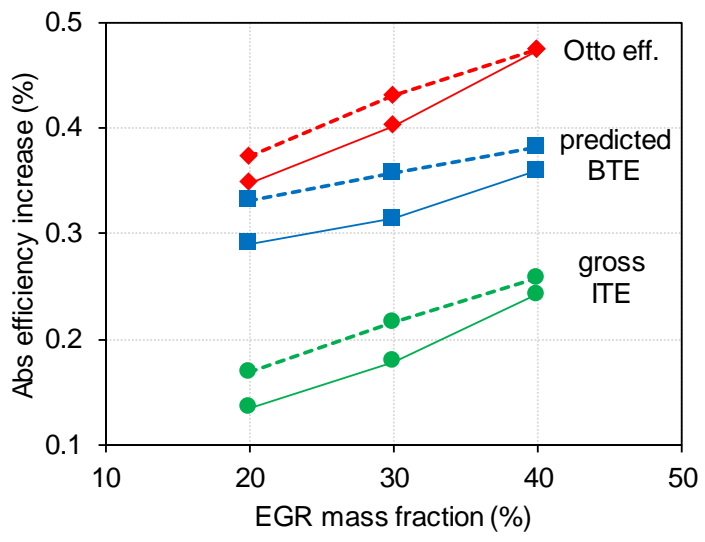

Figure 10: The absolute difference of the Otto cycle efficiency, the gross ITE and the predicted BTE between the R-EGR and the conventional EGR. Solid lines: gross BMEP of 5 bar; dashed lines: gross BMEP of 7 bar.

engine code to evaluate the potential of fuel reforming for increased efficiency.

\section{Full engine cycle simulation}

In this section, the effect of the combustion process, heat transfer, gas exchange, fuel evaporation, and so on were simulated to predict the brake thermal efficiency. The Volvo T3 engine was selected as a case study. This engine was mentioned previously. The experimental results were used to validate the base model. The engine specifications are listed in Table 1. It is a turbocharged direct-injection spark-ignition (DISI) engine, equipped with a highpressure solenoid injector, Bosch HDVE5. The valve timings can be controlled by rotating the camshafts. The standard valve timing is presented in Table 1 . with the opening/closing time being defined at a valve lift of $1 \mathrm{~mm}$. The base valve overlap is $-30 \mathrm{CAD}$. More information about the engine and experimental setup can be found in [14.

\subsection{Methodology}

A commercial one-dimensional engine code, GT-Power, from Gamma Technologies was used. The engine model was built step-by-step. First, the cylinder 
Table 1: Volvo T3 engine specifications

\begin{tabular}{ll}
\hline Engine type & Turbocharged DISI engine \\
\hline Cylinders & 4 in-line \\
Valves & 16 \\
Valvetrain & Double overhead camshaft \\
Bore x Stroke & $79 \times 81.4 \mathrm{~mm}$ \\
Total displacement & $1596 \mathrm{cc}$ \\
CR & $10: 1$ \\
Intake valve phase & $26 \mathrm{CAD}$ aTDC $-50 \mathrm{CAD}$ aBDC \\
Exhaust valve phase & $14 \mathrm{CAD} \mathrm{bBDC}-4 \mathrm{CAD} \mathrm{bTDC}$ \\
Injection timing & $300 \mathrm{CAD} \mathrm{bTDC}$ \\
Injection pressure & $150 \mathrm{bar}$ \\
\hline
\end{tabular}

was constructed with a user-combustion model. A burn rate from the threepressure analysis at full load [14] was implemented. The intake and exhaust systems then were added with correct dimensions, materials and friction coefficients. The gas dynamic model of the engine was calibrated based on the intake and exhaust pressure profiles from experiments. Finally, the combustion model was shifted to a predictive turbulent combustion model, SITurb, in GT-Power. The default laminar burning velocity correlation of methanol was used [45] with an adjustment of the dilution effect multiplier (DEM), see equation 5 in Section 3.1.2. Similar to the previous work of Nguyen et al. [46], the initial flame kernel size was calibrated to match the ignition delay (CA0-2) to the experiments. An initial flame kernel size of $2.6 \mathrm{~mm}$ was used in all simulations. The model of Morel et al. 47] was applied to predict the heat transfer to the walls. The wall temperature was calculated as a function of indicated mean effective pressure (IMEP) [39]. The fuel spray and its evaporation has a strong impact on the gas temperature and the mixing, it followed the settings in the previous work [14. Figure 11 compares the intake and cylinder pressures from simulation and 
experiment at BMEP of 7 bar, $1500 \mathrm{rpm}$, same ignition timing, same throttle position and same valve timing. As can be seen, the simulation is in good agreement with the experiment.

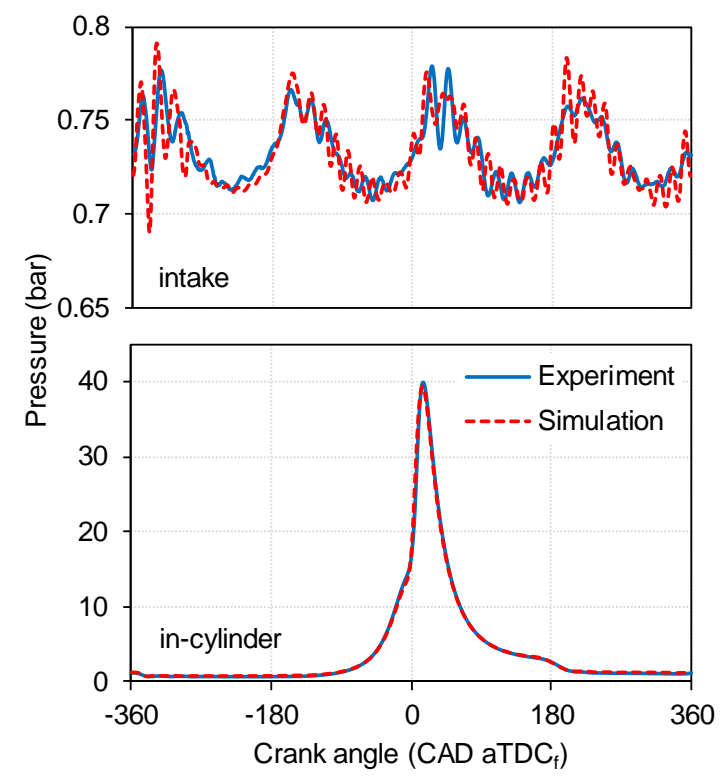

Figure 11: The comparison of the intake and the in-cylinder pressures between simulation and experiment at BMEP of 7 bar, $1500 \mathrm{rpm}$.

\subsubsection{R-EGR engine simulation}

A high pressure (HP) EGR loop was added in the calibrated engine model. The HP-EGR was selected because it provides a higher EGR gas temperature. The reformer catalyst was located inside the EGR loop. The pressure drop over the metal-foam based catalyst was calculated as a function of mass flow rate as in literature 48. The catalyst surface temperature is assumed to be identical to the gas temperature. The gas temperature drops after the catalyst; therefore, an averaged value of the gas temperature before and after the catalyst was used to present the catalyst temperature.

A simple surface reaction mechanism was used to simulate the reforming process. The reaction mechanism includes three main reactions: methanol steam 
reforming, reverse water gas shift and water gas shift reactions. Similar work was done on GT-Power to simulate a $\mathrm{CuO} / \mathrm{ZnO} / \mathrm{Al}_{2} \mathrm{O}_{3}$ catalyst [49] using the power-law reaction rates developed by Purnama et al. [50]. The authors are planing experiments on a $\mathrm{Cu}-\mathrm{Mn}-\mathrm{O}$ metal-foam based catalyst [51]. Unfortunately, no mechanism was developed for that catalyst material. A model with similar settings as in experiment [51] was built in GT-Power, the pre-exponential multiplier of three reactions was calibrated to fit the experimental data. Figure 12a presents the simulated and the measured fuel conversion as a function of the catalyst temperature. The simulation agrees well with the experiment. A higher catalyst temperature results in an increase in fuel conversion. In this simulation, the remaining fuel (fuel conversion $<100 \%$ ) will remain in the original chemical formula $\left(\mathrm{CH}_{3} \mathrm{OH}\right)$, and does not convert to byproducts like $\mathrm{CH}_{4}$ or $\mathrm{HCOOH}$. The reforming products include $\mathrm{H}_{2}, \mathrm{CO}, \mathrm{CO}_{2}$, water vapor and unreacted methanol.

Methanol is able to react with water vapor to form $\mathrm{CO}_{2}$ or it can be dissociated to $\mathrm{CO}$. CO selectivity is used to evaluate the steam reforming performance. It is the volume fraction of $\mathrm{CO}$ to the sum of $\mathrm{CO}$ and $\mathrm{CO}_{2}$. If the $\mathrm{CO}$ selectivity is high, it means methanol is not fully reformed by the steam. In term of energy, the product with a larger CO selectivity has higher energy, which would be better for engine performance. However, in terms of catalyst durability, it is not good due to the absence of water vapor in the reaction, the coking problem can deactivate the catalyst 52 . Figure $12 \mathrm{~b}$ compares the $\mathrm{CO}$ selectivity from simulation and experiment. The simulation is not in perfect agreement with the experiment. However, both experiment and simulation have a very small CO selectivity (less than 5\%), so the difference in the energy of the reforming product can be neglected. The laminar burning velocity is another important parameter. The impact of CO selectivity on the LBV of syngas at stoichiometric conditions was studied and presented in Figure 13 . Because the reforming of methanol and ethanol produces similar products $\left(\mathrm{CO}_{2} / \mathrm{H}_{2}\right.$ molar ratio of $1 / 3$ in $\mathrm{CO}_{2} / \mathrm{H}_{2}$ mixture and $\mathrm{CO} / \mathrm{H}_{2}$ molar ratio of $1 / 2$ in $\mathrm{CO} / \mathrm{H}_{2}$ mixture), the data in Figure 13 is also representative for the LBV of ethanol steam reforming 


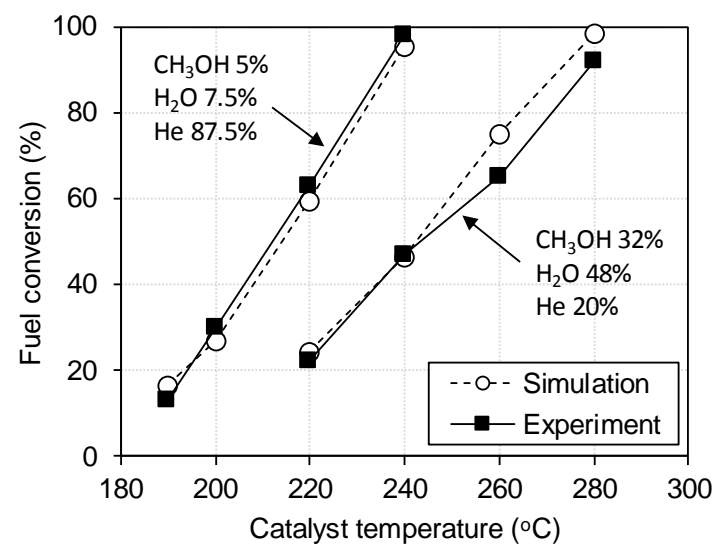

(a) Fuel conversion

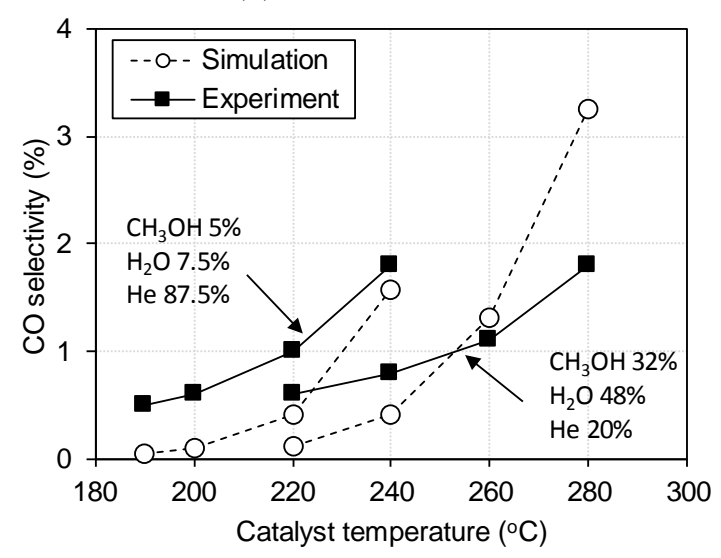

(b) CO selectivity

Figure 12: Comparison of (a) fuel conversion and (b) CO selectivity of the methanol steam reforming over $\mathrm{Cu}-\mathrm{Mn}-\mathrm{O}$ metal-foam based catalyst. Simulation: GT-Power with the updated mechanism, experiment: from [51]. 
CHEM1D code [53] with Li's mechanism [54] and Davis's mechanism [55], and then validated with experiment [56]. Both mechanisms are in the top five best mechanisms for the prediction of syngas LBV [57]. From the simulations, the LBV increases as CO selectivity rises. The experiment on the other hand shows

a CO selectivity less than $20 \%$. This means the updated reaction mechanism can be used with a very small influence on the reactant energy as well as the laminar burning velocity.

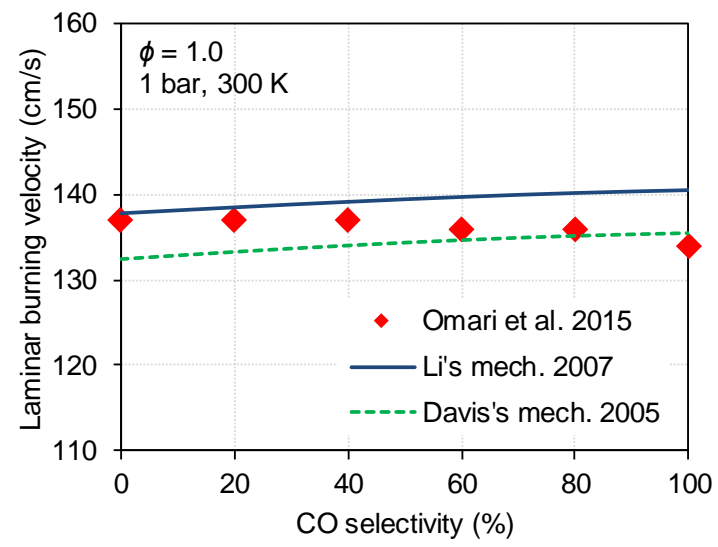

Figure 13: Influence of $\mathrm{CO}$ selectivity on the laminar burning velocity of methanol/ethanol steam reforming products. Diamond symbols: experimental results [56], solid line: simulation results using Li's mech. [54, dashed line: simulation results using Davis's mech. [55].

After the mechanism was validated and implemented into the full engine 465 model, a low pressure injector (the fifth injector) was added to the EGR loop, $300 \mathrm{~mm}$ upstream of the reformer. In this simulation, that injector delivers a similar amount of fuel as the other, high pressure, injectors. The fraction of supplied fuel to the reformer is thus $20 \%$. If the fuel conversion is $80 \%$, the reforming fraction then is $0.8 * 20 \%=16 \%$. A higher fuel fraction could improve the efficiency. However, the fuel conversion decreases, thus the reforming fraction does not change much. In practice, the fuel conversion is influenced by the catalyst temperature, water-to-fuel ratio, and space velocity (ratio of inlet vol- 
umetric flow rate to the catalyst volume). Fuel conversion increases as catalyst temperature and water-to-fuel ratio increase, and as space velocity decreases. To maintain the water-to-fuel ratio with higher delivered rate of fuel, the engine needs to operate at higher EGR ratio. The catalyst volume then also needs to increase in order to maintain the space velocity. The pressure drop over the catalyst would increase; therefore, a higher exhaust pressure would be required. If a back pressure valve is installed in the exhaust pipe, the PMEP increases. Therefore, the fuel fraction for reforming is maintained at $20 \%$ in the present study.

\subsubsection{Dilution term correlation}

In the R-EGR case, the LBV is expected to be higher than for conventional EGR at the same EGR ratio because of the presence of $\mathrm{H}_{2}$ in the reactant. Therefore, the dilution term (ratio of diluted LBV to non-diluted LBV) in the two cases will be different. Since 2015, the dilution term in GT-Power is given by [45]

$$
f(\text { dilution })_{G T}=1-0.75 * D E M *\left(1-(1-0.75 * D E M * \text { dilution })^{7}\right)
$$

where dilution is the mass fraction of residuals in the unburned zone.

In this research, a new dilution term correlation is proposed based on the reactant molar concentrations. The change in mixture concentration with different EGR ratio and reforming fraction can be presented by the variety of $\mathrm{CO}_{2}$, $\mathrm{CO}$ and $\mathrm{H}_{2} \mathrm{O}$ concentrations. Therfore, a new parameter is defined, $\mathrm{X}_{\text {dilution }}=$ $\mathrm{X}_{\mathrm{CO}_{2}}+\mathrm{X}_{\mathrm{CO}}+3 \mathrm{X}_{\mathrm{H}_{2} \mathrm{O}}$. In which, $\mathrm{X}_{\mathrm{CO}_{2}}, \mathrm{X}_{\mathrm{CO}}$ and $\mathrm{X}_{\mathrm{H}_{2} \mathrm{O}}$ is the molar fraction of $\mathrm{CO}_{2}, \mathrm{CO}$ and $\mathrm{H}_{2} \mathrm{O}$ in the reactant, respectively. The dilution term is calculated as in equation 6

$$
f(\text { dilution })_{\text {new }}=a_{1} X_{\text {dilution }}^{2}+a_{2} X_{\text {dilution }}+1
$$

where the coefficients, $a_{1}$ and $a_{2}$, are a function of unburned gas temperature and pressure to fit the results from CHEM1D simulations [53] with a mechanism 
developed by Li et al. [54]:

$$
\begin{array}{r}
a_{1}=-0.0105\left(T_{u}-600\right)+\left(-0.00222 P^{2}+0.200943 P+0.218925\right) \\
a_{2}=0.0045\left(T_{u}-600\right)+\left(0.000842 P^{2}-0.07263 P-2.55193\right)
\end{array}
$$

In the current simulation, the DEM value is manually changed to fit the

500

surface reactions and pressure drop is the same as in the R-EGR simulation.

The EGR ratio is determined by the ratio of mass flow rate of EGR (upstream the EGR injector) to the total mass flow rate of the exhaust gases. 
Figure 14 shows an example of the fuel energy distribution at an EGR raThis means the improvement of BTE is mainly attributed to the reduction of pumping work. The trend and the absolute change of engine efficiency is similar to the findings in the previous analyses.

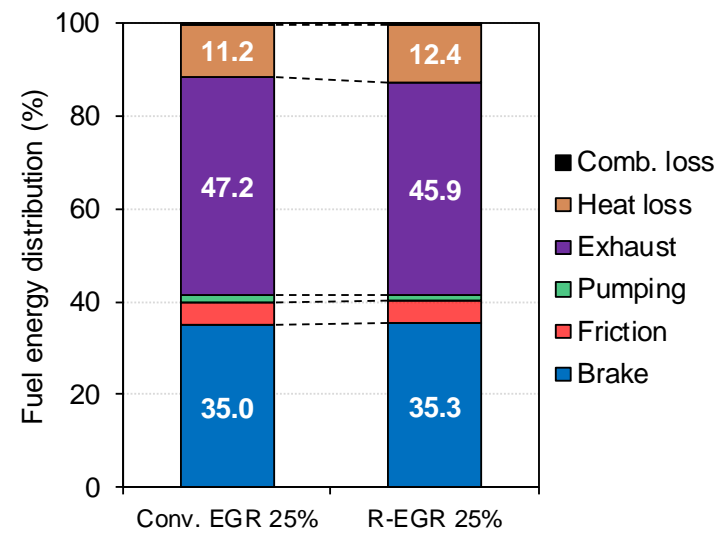

Figure 14: The fuel energy distribution of the conventional EGR and the R-EGR cases at EGR ratio of 25\%, BMEP of 7 bar, $1500 \mathrm{rpm}$.

The relationship between gross ITE and BTE with the change of EGR ratio in the conventional EGR and the R-EGR cases is presented in Figure 15. In 
both cases, gross ITE and BTE increase with higher EGR levels. Compared to the non-diluted case, the boost in the gross ITE at higher EGR ratios is due to the reduction of combustion temperature, enhanced $\gamma$, etc. The difference in gross ITE between the two cases is trivial for the same reason as discussed earlier. The increase of BTE is further attributed to the reduction of pumping work. The pumping work decreases as EGR ratio increases, so the absolute difference between gross ITE and BTE becomes smaller at high EGR ratios. In the conventional EGR cases, The BTE increases by around $2 \%$ points with $27 \%$ EGR. The R-EGR concept got a slightly higher efficiency versus the conventional EGR, the absolute difference is larger at higher EGR ratios. Similar to results of the Otto cycle efficiency calculation (see Figure 7), the efficiency increases little with fuel reforming (versus EGR diluted combustion) and the improvement is more obvious at a higher EGR ratios. This can be explained by a small enhancement of the reformate exergy compared to methanol and the reduction in the MER is less significant at high EGR ratios. Compared to the baseline (no dilution), BTE increases $\sim 5.33 \%$ with EGR and $\sim 6.24 \%$ with R-EGR at an EGR ratio of $25 \%$.

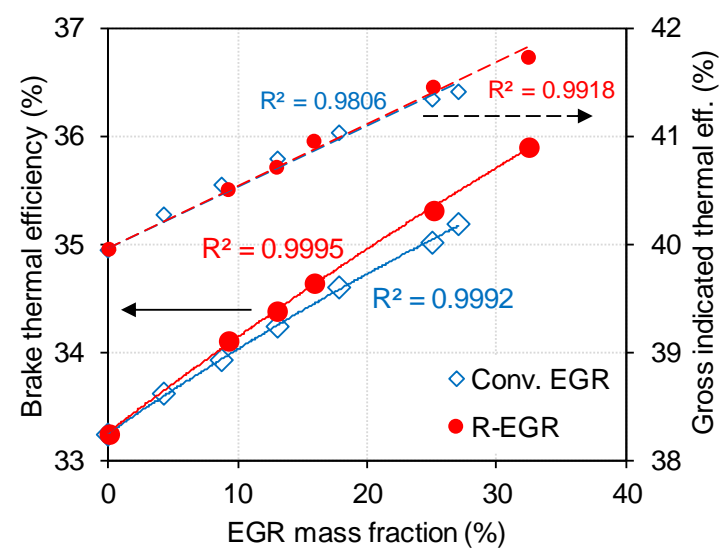

Figure 15: The influence of EGR ratio on the gross indicated thermal efficiency and brake thermal efficiency of the conventional EGR and the R-EGR at BMEP of 7 bar, $1500 \mathrm{rpm}$.

Due to the formation of $\mathrm{H}_{2}$, the LBV increases and it leads to a change in 
the flame development period ( $\mathrm{CA} 0-10$, the duration from ignition timing to the time when $10 \%$ mass is burned) and the combustion duration (CA10-90, mass fraction burn 10\%-90\% duration). Figure 16 shows the CA0-10 (top graph) and CA10-90 (bottom graph) as a function of EGR ratio for both conventional EGR and R-EGR cases. CA0-10 and CA10-90 of the R-EGR cases are shorter than the conventional EGR cases, especially the flame development period. This is due to the increase in LBV. In SI engines, the combustion is first initiated by a laminar flame before it is wrinkled by the in-cylinder turbulence to form a turbulent flame. Therefore, the impact of a difference in LBV on CA0-10 is considerable. The CA10-90 is strongly influenced by the total (turbulent + laminar) flame speed.

To define the combustion stability limit, a CA0-10 limit of $25 \mathrm{CAD}$ was applied. This corresponds to $3 \%$ coefficient of variance of IMEP $\left(\mathrm{COV}_{\text {imep }}\right)$ [61]. As shown in Figure 16, the EGR limit for the conventional EGR is around 25\% and around $28.6 \%$ for the R-EGR (CA0-10 of 25 CAS at these EGR ratios). 575 The estimated BTE at EGR ratio of $28.6 \%$ in the R-EGR case is $\sim 35.6 \%$. The relative increase in BTE is $7.11 \%$ against the baseline, higher than $5.33 \%$ improvement with the EGR dilution at the same combustion stability.

In order to further clarify the impact on burning velocities, Figure 17 presents the laminar and turbulent flame speeds in conventional EGR and R-EGR cases at the same EGR ratio (25\%). The turbulent flame speed depends strongly on the turbulent intensity $\left(u^{\prime}\right)$ in the combustion chamber [45. Because the difference in $u^{\prime}$ after IVC is trivial, the turbulent burning velocities are identical (see Figure 17). Therefore, the absolute difference in total burning velocity is similar to the difference in LBV. The relative change in the total burning velocity with the addition of syngas decreases, which explains for a slight shortening in CA10-90 (see Figure 16). To confirm these estimates, an investigation in an optical SI engine or a three-dimensional simulation using computational fluid dynamics is needed to predict the turbulent intensity and the turbulent flame speed in the combustion chamber. Using a turbulent combustion model which so takes fuel properties into account also can be used to predict the change of total 

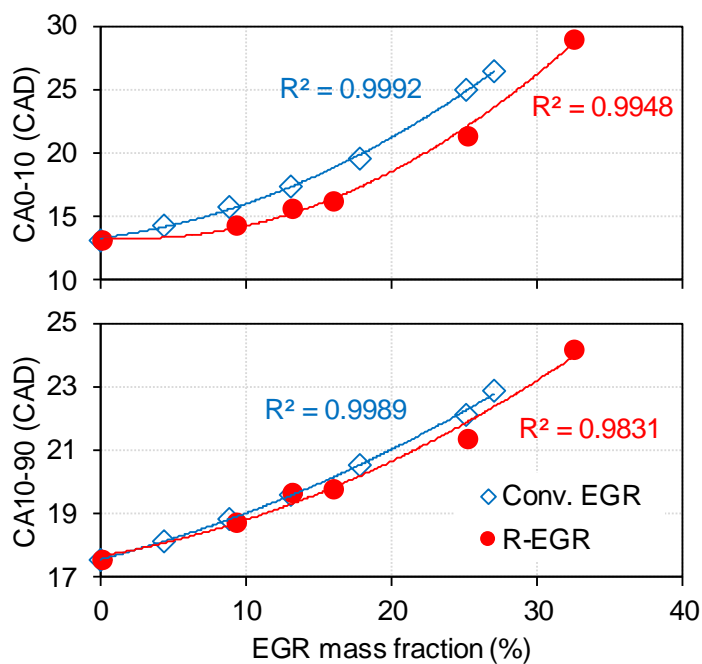

Figure 16: The comparison of flame development period (CA0-10) and combustion duration (CA10-90) between the conventional EGR and the R-EGR at BMEP of 7 bar, $1500 \mathrm{rpm}$.

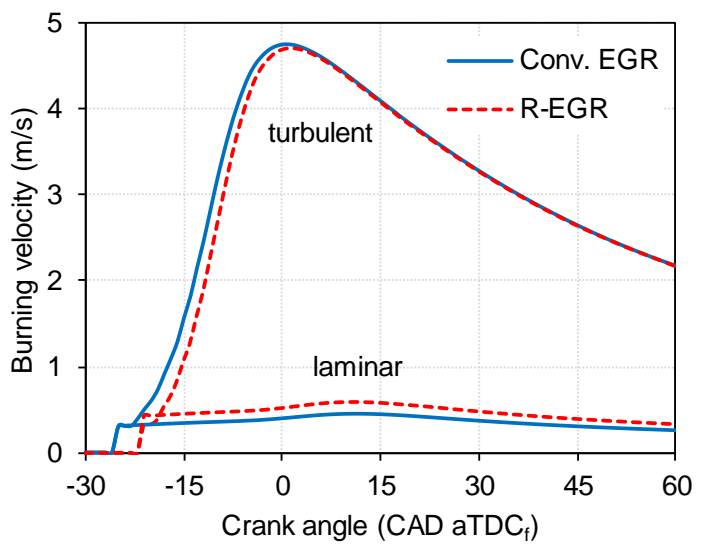

Figure 17: The instantaneous burning velocities in the conventional EGR and the R-EGR at EGR ratio of 25\%, BMEP of 7 bar, $1500 \mathrm{rpm}$. 
flame speed [46].

Figure 18 compares the in-cylinder cumulative heat release at EGR ratio of $25 \%$ between two cases. Although the total amount of fuel decreases, total heat release improves in the R-EGR case. Due to the increased LHV of the reforming products, the combustion releases more heat than the conventional one. This leads to an increase in the burned gas temperature $\left(T_{b}\right)$, see Figure 19 . The combustion starts later in the R-EGR case (later MBT ignition timing) and the burned zone temperature is higher. There are two reasons for this: more heat is released during the combustion and a higher initial temperature (see unburned gas temperature $T_{u}$ ). The increase in $T_{u}$ in the R-EGR cases can be explained by a higher $\gamma$ during the compression stroke.

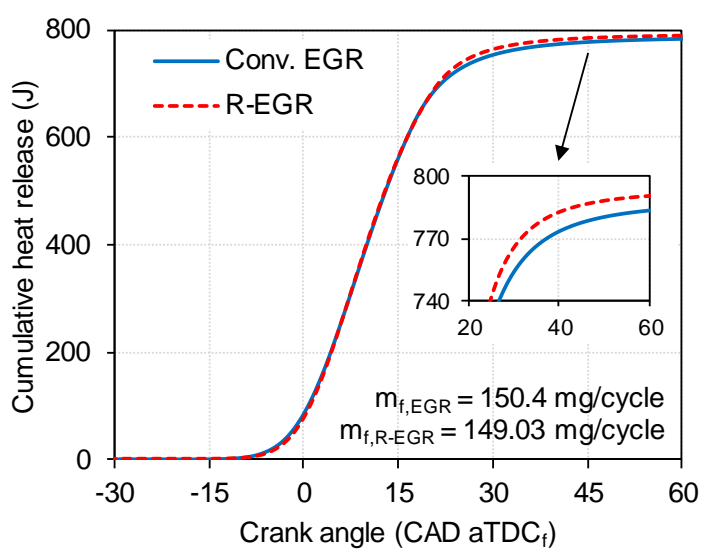

Figure 18: The cumulative heat release of the conventional EGR and the R-EGR at EGR ratio of $25 \%$, BMEP of 7 bar, $1500 \mathrm{rpm}$.

Figure 20 shows the in-cylinder $\gamma$ in the conventional EGR and the R-EGR cases versus crank angle at the same EGR ratio of 25\%. At the beginning, $\gamma$ increases during the intake stroke. Before the start of injection, the R-EGR case has a slightly higher $\gamma$ than conventional EGR due to the presence of $\mathrm{H}_{2}$ and the reduction of $\mathrm{H}_{2} \mathrm{O}$ in the inlet. After injection, $\gamma$ decreases significantly because of a high specific heat $C_{p}$ of the liquid fuel. Thanks to the cooling effect, $\gamma$ improves again after the end of injection. Less fuel is injected directly 


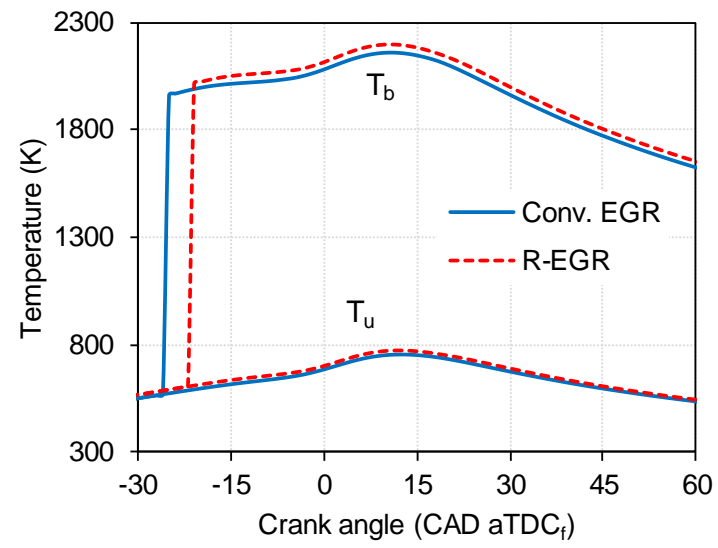

Figure 19: The burned and unburned gas temperatures of the conventional EGR and the R-EGR at EGR ratio of 25\%, BMEP of 7 bar, $1500 \mathrm{rpm}$.

to the cylinder in the R-EGR cases $(\sim 80 \%)$, this clarifies a higher $\gamma$. The unburned gas temperature and pressure after the compression are higher with fuel reforming. After the ignition, the $\gamma$ decreases sharply because of high combustion temperatures. As shown in Figure 19, the combustion temperature increases in the R-EGR case, that case has lower $\gamma$ values during the expansion and the exhaust strokes. Due to the increase of combustion temperature, it explains the increase in relative heat transfer.

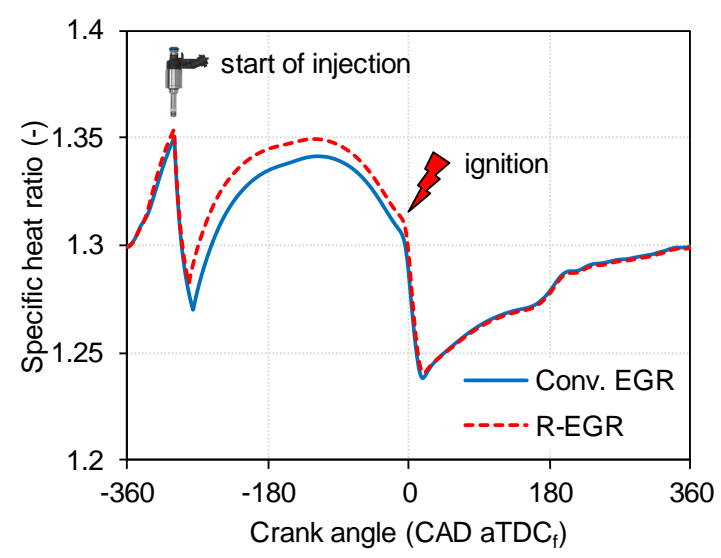

Figure 20: The in-cylinder specific heat ratio of the conventional EGR and the R-EGR at EGR ratio of $25 \%$, BMEP of 7 bar, $1500 \mathrm{rpm}$. 
Although there are some uncertainties in the full engine simulation such as the turbulence, combustion, heat transfer, and so on, the full engine simulation results further confirm the conclusion from the Otto cycle calculation. The limited increase in exergy of the reformate is the key reason. Fuel effects will be presented in the following section to find the most interesting fuel for the R-EGR concept.

\section{Fuel effects}

Methanol is the most promising e-fuel and it is easy to reform. However, only a small increase in reformate exergy results in a limited relative increase in engine efficiency. Fuels which have higher exergy increase in the reforming products such as ethanol and iso-octane (gasoline surrogate) seem to have more potential. Chakravarthy et al. analyzed the fundamental thermodynamics of thermochemical recuperation for a range of fuels. They concluded that the relative improvement of the cycle work of methanol reforming is less than ethanol and iso-octane at the same reforming fraction, 95\% 62]. The absolute efficiency of the system and the difficulty of fuel reforming were not considered in that research. The steam reforming of methanol takes place in the temperature range $\sim 500-600 \mathrm{~K}$, significantly lower than the required temperature for ethanol ( $\sim 800-1000 \mathrm{~K})$ and for gasoline $(\sim 1000-1150 \mathrm{~K})$ [63. It means that the catalyst requires $\sim 23-27 \%, 34-43 \%$, and $42-48 \%$ heat from the adiabatic combustion of these fuels for reforming.

In this research, the idealized Otto cycle efficiency is employed because this gave more or less the same trends and the same absolute efficiency improvement as the complete engine simulation. This research focuses on the maximum efficiency of the R-EGR concept that can be achieved for different fuels at the same combustion stability limit. Table 2 shows the theoretical reforming reactions of three fuels with the enthalpy of formation, the LHV increase and the exergy increase of the reforming products. The enthalpy of formation here was calculated with the fuel and the water in the gas phase, the required enthalpy 
for vaporization was neglected.

\begin{tabular}{llcccl}
\hline Fuel & Reaction & $\Delta \mathrm{h}(\mathrm{kJ} / \mathrm{kmol})$ & LHV & Exergy & Name \\
\hline \multirow{2}{*}{ Methanol } & $\mathrm{CH}_{3} \mathrm{OH}+\mathrm{CO}_{2} \leftrightarrow 2 \mathrm{CO}+3 \mathrm{H}_{2}+\mathrm{H}_{2} \mathrm{O}$ & +131 & $+26 \%$ & $+9.3 \%$ & MeOH-Dry \\
& $\mathrm{CH}_{3} \mathrm{OH}+\mathrm{H}_{2} \mathrm{O} \leftrightarrow \mathrm{CO}_{2}+3 \mathrm{H}_{2}$ & +49 & $+13 \%$ & $+1 \%$ & Methanol \\
\hline \multirow{2}{*}{ Ethanol } & $\mathrm{C}_{2} \mathrm{H}_{5} \mathrm{OH}+\mathrm{CO}_{2} \leftrightarrow 3 \mathrm{CO}+3 \mathrm{H}_{2}$ & +297 & $+27 \%$ & $+11 \%$ & EtOH-Dry \\
& $\mathrm{C}_{2} \mathrm{H}_{5} \mathrm{OH}+\mathrm{H}_{2} \mathrm{O} \leftrightarrow 2 \mathrm{CO}+4 \mathrm{H}_{2}$ & +256 & $+23.5 \%$ & $+8.8 \%$ & EtOH-CO \\
& $\mathrm{C}_{2} \mathrm{H}_{5} \mathrm{OH}+3 \mathrm{H}_{2} \mathrm{O} \leftrightarrow 2 \mathrm{CO}_{2}+6 \mathrm{H}_{2}$ & +173 & $+16.5 \%$ & $+4.25 \%$ & EtOH-CO2 \\
\hline \multirow{2}{*}{ Octane } & $\mathrm{C}_{8} \mathrm{H}_{18}+8 \mathrm{CO}_{2} \leftrightarrow 16 \mathrm{CO}+9 \mathrm{H}_{2}$ & +1588 & $+31.8 \%$ & $+17.8 \%$ & Octane-Dry \\
& $\mathrm{C}_{8} \mathrm{H}_{18}+8 \mathrm{H}_{2} \mathrm{O} \leftrightarrow 8 \mathrm{CO}+17 \mathrm{H}_{2}$ & +1259 & $+25 \%$ & $+13.2 \%$ & Octane-CO \\
& $\mathrm{C}_{8} \mathrm{H}_{18}+16 \mathrm{H}_{2} \mathrm{O} \leftrightarrow 8 \mathrm{CO}_{2}+25 \mathrm{H}_{2}$ & +930 & $+18.3 \%$ & $+8.6 \%$ & Octane-CO2 \\
\hline
\end{tabular}

The exhaust includes $\mathrm{H}_{2} \mathrm{O}$ and $\mathrm{CO}_{2}$ which can react with the fuel to produce syngas through steam reforming or dry reforming. As can be seen in the Table, the enthalpy of formation for dry reforming is much higher than the steam reforming. Therefore, the effect of $\mathrm{CO}_{2}$ on the reforming process was neglected, only steam reforming was considered. There are two possibilities of steam reforming of ethanol and iso-octane, the product can be a mixture of $\mathrm{H}_{2} / \mathrm{CO}$ or $\mathrm{H}_{2} / \mathrm{CO}_{2}$. These reactions were named depending on the input fuel (EtOH stands for ethanol) and the second product $\left(\mathrm{CO}\right.$ or $\left.\mathrm{CO}_{2}\right)$. To produce a mixture of $\mathrm{H}_{2}$ and $\mathrm{CO}_{2}$, less energy is required. This leads to a reduction in LHV and exergy for the reactions which have $\mathrm{CO}_{2}$ in the reforming products. The combustion reactions for 4 cases (two for ethanol and two for iso-octane) were calculated, similar to the methanol calculation (reaction R3) in the previous part. Less water is required to reform the fuel into CO. Byproducts like $\mathrm{CH}_{4}$ were not considered in this research. Similar to the work on methanol, the reforming starts at EGR ratio $\geqslant 20 \%$. Similar to the previous calculation, the same compression ratio (9:1), initial pressure (1 bar) and initial temperature (343 K) were used. 
Figure 21a illustrates the Otto cycle efficiency of the R-EGR engine with different fuels as a function of the reforming fraction at $20 \% \mathrm{EGR}$. The reforming fraction is limited in some cases because of the lack of water vapor. As seen in the Table 2, to reform one mole of fuel, one mole of water is needed to reform methanol and reform ethanol to $\mathrm{H}_{2} / \mathrm{CO}$ mixutre (EtOH-CO). Therefore, the reforming fraction in these cases can be increased to 50\%. The EtOH-CO2, Octane- $\mathrm{CO}$ and Octane-CO2 cases require respectively 3 moles, 8 moles and 16 moles of water to reform one mole of fuel, so the reforming fraction of these three cases are limited. Without reforming, the efficiency of methanol is the highest because methanol has the highest exergy-to-energy ratio [3]. However, the efficiency increases slowly with higher reforming fractions. Ethanol and especially iso-octane has a better improvement rate, represented by the slope of the lines. The case which has a higher exergy increase (see Table 2 will have a higher relative efficiency improvement. Because of the water limit at an EGR ratio of $20 \%$, the comparison at $50 \%$ EGR was added. At $50 \%$ EGR, there is enough water to reform up to $50 \%$ ethanol and iso-octane, see Figure $21 \mathrm{~b}$

Although the original efficiency of ethanol and iso-octane is lower than methanol, the efficiency of EtOH-CO, EtOH-CO2 and Octane-CO becomes higher than methanol at reforming fractions of $50 \%$. This is likely due to the significant improvement of exergy. Depending on the reforming product, ethanol engines could have a higher efficiency than methanol engines if more than $20-35 \%$ of fuel would be fully reformed.

685

In order to compare the maximum efficiency that be achieved with the REGR engine concept, ethanol cases were selected to compare with methanol. Previously, the comparison was done at the same EGR ratio and the same reforming fraction, i.e. the combustion stability limit was not considered. To determine the combustion stability limit, a constant laminar burning velocity ${ }_{690}$ is used [43. The laminar burning velocity of the methanol-air flames at $25 \%$ EGR (dilution limit in section 3.2) at post-compressed condition $\left(\mathrm{P}_{1}\right.$ and $\mathrm{T}_{1}$ from the Otto cycle) is employed to set the limit of LBV. The LBV is calculated using the code [53] at that condition using Li's mechanism [54, and equals 36 


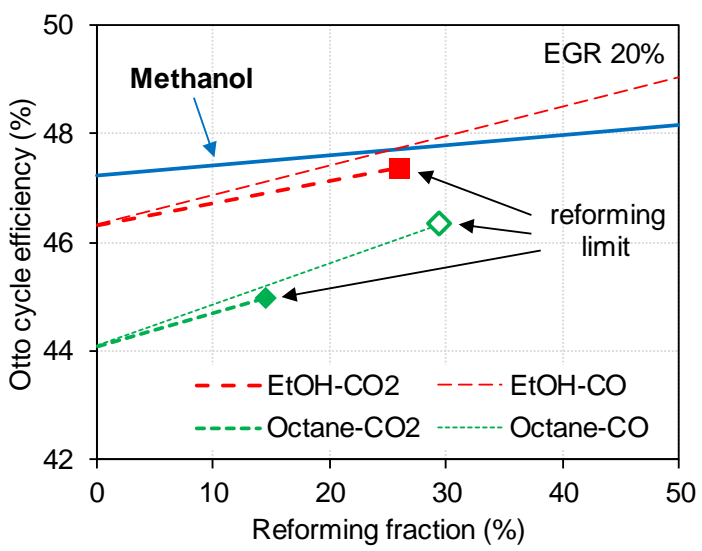

(a) Comparison at $20 \%$ EGR

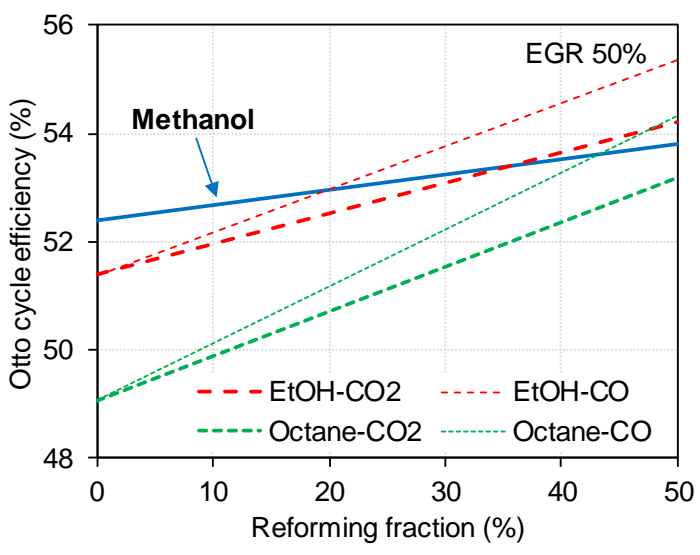

(b) Comparison at 50\% EGR

Figure 21: The Otto cycle efficiency of methanol, ethanol and iso-octane engines as a function of reforming fraction. 
$\mathrm{cm} / \mathrm{s}$. For the ethanol cases, the laminar burning velocity was calculated using a different mechanism which was developed by the same group [64]. The LBV limit decreases as a higher value of $\mathrm{COV}_{\text {imep }}$ is used, such as $5 \%$ or $10 \%$.

Figure 22 shows the EGR limit, defined in this way, of the methanol, EtOH$\mathrm{CO} 2$ and $\mathrm{EtOH}-\mathrm{CO}$ cases versus the reforming fraction. For the methanol case, the EGR limit is $25 \%$ without reforming, and it increases up to $\sim 35.7 \%$ at a reforming fraction of $50 \%$. This is due to a faster LBV of syngas versus methanol 44. As seen in this Figure, at the reforming fraction of 20\%, the EGR limit for the R-EGR case is around 29\%, similar to the result (28.6\%) in Figure 16 . Ethanol has a slower LBV compared to methanol [65, thus the dilution limit is lower, around 20\% EGR without reforming. At increased reforming fraction, the EGR limit enhances significantly and reaches a higher dilution limit than methanol ( $\sim 36.7 \%$ versus $35.7 \%$ for methanol) at the reforming fraction of $50 \%$. The EGR limit in the two ethanol cases overlap each other because the LBV of the syngas is almost independent on the CO selectivity (see Figure 13). Ethanol reforming produces double the amount of syngas versus methanol (Table 2), so the syngas/fuel molar ratio in ethanol cases are higher at the same reforming fraction. This leads to a sharper boost in the dilution limit.

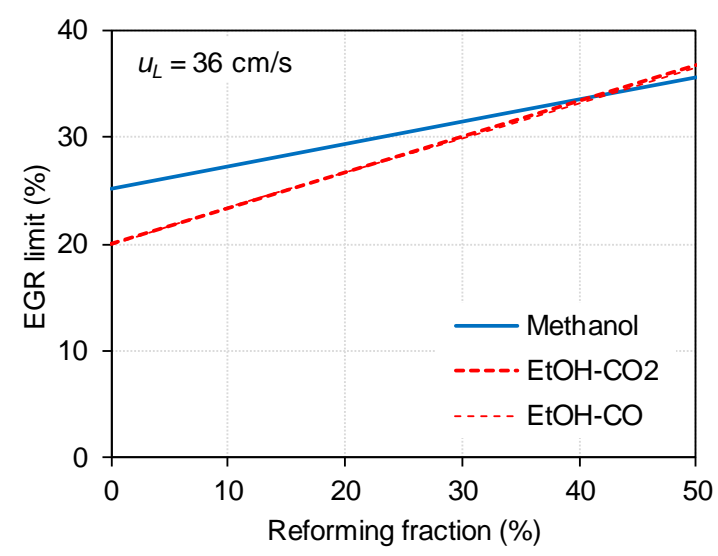

Figure 22: The EGR limit of Methanol, EtOH-CO2 and EtOH-CO versus reforming fraction (same laminar burning velocity of $36 \mathrm{~cm} / \mathrm{s}$ ). 
Figure 23 shows the maximum Otto cycle efficiency of the methanol, EtOH$\mathrm{CO} 2$ and EtOH-CO cases at the combustion stability limit against the reforming fraction. Although the two ethanol cases have the same dilution limit, the maximum efficiency in the EtOH-CO case is higher due to the increase of LHV with CO selectivity of $100 \%$. Without reforming and without EGR, there is a small difference in Otto cycle efficiency between methanol and ethanol, $43.77 \%$ versus $42.86 \%$. The maximum efficiency increases up to $48.12 \%$ for methanol and $46.28 \%$ for ethanol without reforming. The efficiency can be improved to $51.12 \%, 52.57 \%$ and $51.45 \%$ for methanol, EtOH-CO2 and EtOH-CO respectively if $50 \%$ of fuel is fully reformed. Higher efficiency can be observed with ethanol if the catalyst can reform over $\sim 30 \%$ and $\sim 40 \%$ fuel to $\mathrm{H}_{2}$-CO and $\mathrm{H}_{2}-\mathrm{CO}_{2}$ mixture, respectively. The efficiency of an R-EGR ethanol engine is somewhere between the two dashed lines, it depends on the CO selectivity.

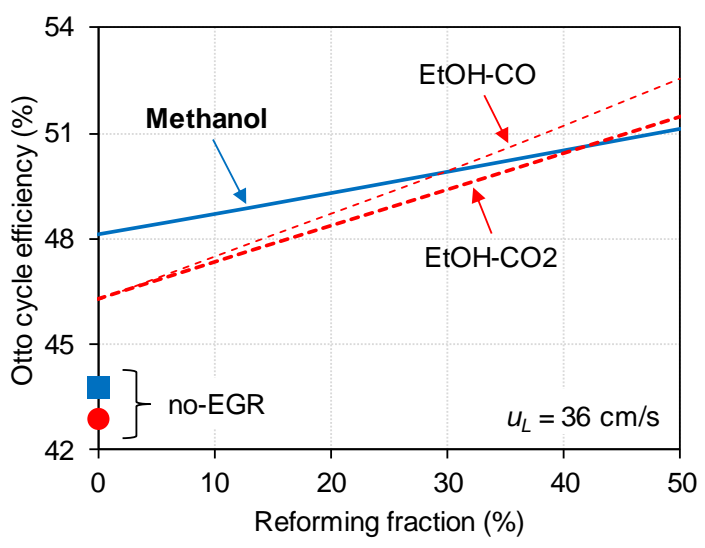

Figure 23: The maximum Otto cycle efficiency of Methanol, EtOH-CO2 and EtOH-CO at the same combustion stability limit.

In this analysis, the difficulty of fuel reforming, especially for ethanol and iso-octane was not considered. In practice, due to high reforming temperatures for ethanol and iso-octane, the degree of reforming of these fuels will be less than methanol. The required reforming fraction of ethanol is between $30 \%$ to $40 \%$, which is not easy to achieve with normal temperatures of the engine exhaust 
has a better knock resistance than ethanol [66], together with a higher HoV, so the compression ratio of a methanol engine can be increased to a higher value than for an ethanol engine. If the $\mathrm{CR}$ was optimized for methanol and ethanol engines, the efficiency of the methanol engine should be highest even at high

\section{Conclusions}

Theoretical studies have been carried out to evaluate the potential of the reformed-exhaust gas recirculation (R-EGR) concept for achieving high fuel economy with methanol SI engines. An Otto cycle calculation was used first and then a full engine simulation with GT-Power was employed. The Otto cycle efficiency was also extended with a simple analysis of energy losses, performed to predict the change in engine BTE using specifications of a production DISI engine (Volvo T3). That engine then was simulated using GT-Power. A HPEGR loop was constructed in the model with a reformer catalyst inside. A new dilution term correlation was developed based on the reactant concentrations. Finally, fuel effects were investigated to select the most promising fuel for the R-EGR engine concept. Based on the results, the following conclusions can be drawn.

- Combustion in the R-EGR cases produces higher temperatures and lower pressures than the conventional EGR if the initial pressure is identical. Raising EGR levels and reforming fractions cause a decline in the cycle work.

- For a given EGR ratio, reforming fraction does not have a significant impact on the efficiency. The improvement is smaller at lower EGR ratios. 
- The R-EGR case has higher relative heat loss than the conventional EGR. There is almost no difference in the gross ITE between the R-EGR and conventional EGR.

- The main contributor for the increase of BTE is the reduction of pumping work. The BTE increases by $\sim 0.3 \%$ absolute compared to the conventional EGR at EGR ratio of $25 \%$.

- The flame development period (CA0-10) and combustion duration (CA1090) reduce with the presence of $\mathrm{H}_{2}$ in the EGR mixture.

- A CA0-10 of 25 CAD is used as the combustion limit, it corresponds with $\mathrm{COV}_{\text {imep }}$ of $3 \%$. At the EGR limits, BTE relatively increases $5.33 \%$ and 7.11\% compared to the baseline with the dilution of EGR and R-EGR mixture, respectively.

- The combustion in the R-EGR case releases more heat than the conventional EGR. Therefore, the combustion temperature is higher in the R-EGR cases, leading to a higher heat loss to the walls.

- The specific heat ratio rises in the R-EGR case due to the presence of $\mathrm{H}_{2}$ in the reactant and less liquid fuel is injected during the intake stroke.

- Ethanol and iso-octane have a larger relative improvement in the efficiency at the same reforming fraction versus methanol. High reforming fractions $(30-40 \%)$ of ethanol are required to achieve a similar efficiency as methanol.

- The methanol engine would be able to produce a higher efficiency than the ethanol engine if the optimal CR was used and the difficulty of ethanol reforming was considered.

\section{Acknowledgments}

The financial supports from the Special Research Fund (BOF) of Ghent University (grant no. 01N03013) and GOA project (BOF16/GOA/004) are 


\section{References}

[1] M. De Cesare, N. Cavina, L. Paiano, Technology Comparison for Spark Ignition Engines of New Generation, SAE International Journal of Engines 10 (2017) 2513-2534. doi:10.4271/2017-24-0151.

[7] R. Backhaus, Alternative fuels $\mathrm{CO}_{2}-$ neutral into the future, MTZ worldwide 78 (6) (2017) 8-13. doi:10.1007/s38313-017-0066-1.

[8] M. Härtl, A. Stadler, F. Backes, G. Wachtmeister, E. Jacob, Potentially $\mathrm{CO}_{2}$-neutral fuels for clean SI engines, MTZ worldwide 78 (7-8) (2017)

2] J. A. Caton, Implications of fuel selection for an SI engine: Results from the first and second laws of thermodynamics, Fuel 89 (11) (2010) 3157-3166. doi:10.1016/j.fuel.2010.05.005

[3] J. P. Szybist, K. Chakravathy, C. S. Daw, Analysis of the Impact of Selected Fuel Thermochemical Properties on Internal Combustion Engine Efficiency, Energy \& Fuels 26 (5) (2012) 2798-2810. doi:10.1021/ef2019879

[4] M. Westerhoff, Sustainable Mobility Requires Synthetic Fuels, MTZ worldwide 78 (5) (2017) 8-15. doi:10.1007/s38313-017-0050-9

[5] L. Hentschel, K. Michels, T. Garbe, M. Hönig, E-fuels - a central module for future engine design?, in: Internationaler Motorenkongress 2018, 2018, pp. 487-489. doi:10.1007/978-3-658-21015-1_32.

[6] R. L. McCormick, G. M. Fioroni, M. A. Ratcliff, R. W. Grout, J. P. Szybist, C. Mueller, G. Lacaze, T. Bays, W. Pitz, M. Mehl, S. W. Wagnon, M. J. McNenly, Fuel Property Characterization and Prediction, in: Vehicle Technologies Office (VTO) Annual Merit Review and Peer Evaluation, 2017.

76-83. doi:10.1007/s38313-017-0058-1. 
[9] M. E. Bardin, E. V. Ivanov, E. J. Nilsson, V. A. Vinokurov, A. A. Konnov, Laminar burning velocities of dimethyl carbonate with air, Energy \& Fuels 27 (9) (2013) 5513-5517. doi:10.1021/ef401108a.

[10] E. Ranzi, A. Frassoldati, R. Grana, A. Cuoci, T. Faravelli, A. Kelley, C. Law, Hierarchical and comparative kinetic modeling of laminar flame speeds of hydrocarbon and oxygenated fuels, Progress in Energy and Combustion Science 38 (4) (2012) 468-501. doi:10.1016/j.pecs.2012.03. 004.

[11] J. Vancoillie, J. Demuynck, L. Sileghem, M. V. D. Ginste, S. Verhelst, L. Brabant, L. V. Hoorebeke, The potential of methanol as a fuel for flexfuel and dedicated spark-ignition engines, Applied Energy 102 (2013) 140 - 149. doi:10.1016/j.apenergy.2012.05.065.

[12] J. Vancoillie, J. Demuynck, L. Sileghem, M. V. D. Ginste, S. Verhelst, Comparison of the renewable transportation fuels, hydrogen and methanol formed from hydrogen, with gasoline - Engine efficiency study, International Journal of Hydrogen Energy 37 (12) (2012) 9914 - 9924. doi: $10.1016 / j . i j h y d e n e .2012 .03 .145$

[13] L. Sileghem, A. Ickes, T. Wallner, S. Verhelst, Experimental investigation of a DISI production engine fuelled with methanol, ethanol, butanol and iso-stoichiometric alcohol blends, SAE Technical Paper 2015-01-0768doi: 10.4271/2015-01-0768.

[14] D.-K. Nguyen, T. Van Craeynest, T. Pillu, J. Coulier, S. Verhelst, Downsizing Potential of Methanol Fueled DISI Engine with Variable Valve Timing and Boost Control, SAE Technical Paper 2018-01-0918doi:10.4271/ 2018-01-0918.

[15] L. Tartakovsky, M. Sheintuch, Fuel reforming in internal combustion engines, Progress in Energy and Combustion Science 67 (2018) 88-114. doi:10.1016/j.pecs.2018.02.003 
[16] J. G. Finegold, J. T. McKinnon, Dissociated methanol test results, in: Biomass to Methanol Workshop.

[17] E. Anthonissen, J. Wallace, Dissociated methanol engine testing results using $\mathrm{H}_{2} / \mathrm{CO}$ mixtures, Proc., Intersoc. Energy Convers. Eng. Conf.; (United States) 2 .

[18] J. G. Finegold, Dissociated methanol vehicle test results, in: VI International Symposium on Alcohol Fuels Technology.

[19] N. D. Brinkman, R. F. Stebar, A Comparison of Methanol and Dissociated Methanol Illustrating Effects of Fuel Properties on Engine Efficiency-Experiments and Thermodynamic Analyses, SAE Technical Paper 850217doi:10.4271/850217.

[20] B. Lindner, K. Sjöström, Operation of an internal combustion engine: lean conditions with hydrogen produced in an onboard methanol reforming unit, Fuel 63 (11) (1984) 1485-1490. doi:10.1016/0016-2361(84)90211-4.

[21] L. Pettersson, K. Sjöström, An experimental and theoretical evaluation of the onboard decomposed methanol spark-ignition engine, Combus855 \ tion Science and Technology 71 (1-3) (1990) 129-143. doi:10.1080/ 00102209008951628

[22] A. Poran, A. Thawko, A. Eyal, L. Tartakovsky, Direct injection internal combustion engine with high-pressure thermochemical recuperationExperimental study of the first prototype, International Journal of Hydrogen Energy 43 (2018) 11969-11980. doi:10.1016/j.ijhydene.2018.04. 190.

[23] L. Tartakovsky, R. Amiel, V. Baibikov, R. Fleischman, M. Gutman, A. Poran, M. Veinblat, SI engine with direct injection of methanol reforming products-first experimental results, SAE Technical Paper 2015-320712 doi:10.4271/2015-32-0712. 
[24] A. Poran, L. Tartakovsky, Performance and emissions of a direct injection internal combustion engine devised for joint operation with a high-pressure thermochemical recuperation system, Energy 124 (2017) 214-226. doi: $10.1016 / j$.energy . 2017.02.074.

[25] A. Poran, L. Tartakovsky, Influence of methanol reformate injection strategy on performance, available exhaust gas enthalpy and emissions of a direct-injection spark ignition engine, International Journal of Hydrogen Energy 42 (23) (2017) 15652-15668. doi:10.1016/j.ijhydene.2017.05. 056.

[26] E. G. Lim, E. E. Dames, K. D. Cedrone, A. J. Acocella, T. R. Needham, A. Arce, D. R. Cohn, L. Bromberg, W. K. Cheng, W. H. Green, The engine reformer: Syngas production in an engine for compact gas-to-liquids synthesis, The Canadian Journal of Chemical Engineering 94 (4) (2016) 623-635. doi:10.1002/cjce.22443

[27] S. Wiemann, R. Hegner, B. Atakan, C. Schulz, S. A. Kaiser, Combined production of power and syngas in an internal combustion engineExperiments and simulations in SI and HCCI mode, Fuel 215 (2018) 40-45. doi:10.1016/j.fuel.2017.11.002

[28] T. Alger, B. Mangold, Dedicated EGR: a new concept in high efficiency 85 engines, SAE International Journal of Engines 2 (2009) 620-631. doi: 10.4271/2009-01-0694.

[29] E. Randolph, R. Gukelberger, T. Alger, T. Briggs, C. Chadwell, A. Bosquez Jr, Methanol Fuel Testing on Port Fuel Injected InternalOnly EGR, HPL-EGR and D-EGRß Engine Configurations, SAE International Journal of Fuels and Lubricants 10 (3) (2017) 718-727. doi: 10.4271/2017-01-2285.

[30] P. Leung, A. Tsolakis, J. Rodríguez-Fernández, S. Golunski, Raising the fuel heating value and recovering exhaust heat by on-board oxidative re- 
forming of bioethanol, Energy \& Environmental Science 3 (6) (2010) 780788. doi:10.1039/B927199F

[31] Y. Chang, J. P. Szybist, J. A. Pihl, D. W. Brookshear, Catalytic Exhaust Gas Recirculation-Loop Reforming for High Efficiency in a Stoichiometric Spark-Ignited Engine through Thermochemical Recuperation and Dilution Limit Extension, Part 1: Catalyst Performance, Energy \& Fuels 32 (2) (2018) 2245-2256. doi:10.1021/acs .energyfuels.7b02564.

[32] Y. Chang, J. P. Szybist, J. A. Pihl, D. W. Brookshear, Catalytic Exhaust Gas Recirculation-Loop Reforming for High Efficiency in a Stoichiometric Spark-Ignited Engine through Thermochemical Recuperation and Dilution Limit Extension, Part 2: Engine Performance, Energy \& Fuels 32 (2) (2018) 2257-2266. doi:10.1021/acs.energyfuels.7b02565.

[33] D. Fennell, J. M. Herreros, A. Tsolakis, H. Xu, K. Cockle, P. Millington, GDI engine performance and emissions with reformed exhaust gas recirculation (REGR), SAE Technical Paper 2013-01-0537doi:10.4271/ 2013-01-0537.

[34] D. Fennell, J. Herreros, A. Tsolakis, Improving gasoline direct injection (GDI) engine efficiency and emissions with hydrogen from exhaust gas fuel reforming, International Journal of Hydrogen Energy 39 (10) (2014) 51535162. doi:10.1016/j.ijhydene.2014.01.065.

[35] M. Bogarra-Macias, J. M. M. Herreros-Arellano, A. Tsolakis, A. P. York, P. Millington, Reformate Exhaust Gas Recirculation (REGR) Effect on Particulate Matter (PM), Soot Oxidation and Three Way Catalyst (TWC) Performance in Gasoline Direct Injection (GDI) Engines, SAE International Journal of Engines 9 (1) (2016) 305-314. doi:10.4271/2015-01-2019.

[36] D. Fennell, J. M. Herreros Arellano, A. Tsolakis, M. Wyszynski, K. Cockle, J. Pignon, P. Millington, On-board thermochemical energy recovery technology for low carbon clean gasoline direct injection engine powered ve- 
hicles, Proceedings of the Institution of Mechanical Engineers, Part D: Journal of Automobile Engineering 232 (8) (2018) 1079-1091.

[37] K. Ashida, H. Maeda, T. Araki, M. Hoshino, K. Hiraya, T. Izumi, M. Yasuoka, Study of an on-board fuel reformer and hydrogen-added EGR combustion in a gasoline engine, SAE International Journal of Fuels and Lubricants 8 (2015) 358-366. doi:10.4271/2015-01-0902.

[38] G. F. Hohenberg, Advanced approaches for heat transfer calculations, SAE Technical Paper 790825 doi:10.4271/790825.

[39] S. Richard, S. Bougrine, G. Font, F.-A. Lafossas, F. Le Berr, On the reduction of a 3D CFD combustion model to build a physical 0D model for simulating heat release, knock and pollutants in SI engines, Oil \& Gas Science and Technology-Rev. IFP 64 (3) (2009) 223-242. doi:10.2516/ogst/ 2008055

${ }_{935}$ [40] J. A. Caton, Maximum efficiencies for internal combustion engines: Thermodynamic limitations, International Journal of Engine Research (2017) 1468087417737700 doi:10.1177/1468087417737700.

[41] J. Caton, First and second law implications of fuel selection for an SI engine, in: 2010 Spring Technical Meeting of the Central States Section of the Combustion Institute, 2010.

[42] S. K. Chen, P. F. Flynn, Development of a single cylinder compression ignition research engine, SAE Technical Paper 650733doi:10.4271/650733.

[43] D.-K. Nguyen, S. Verhelst, Computational Study of the Laminar Reaction Front Properties of Diluted Methanol-Air Flames Enriched by the Fuel Reforming Product, Energy \& Fuels 31 (9) (2017) 9991-10002. doi:10. 1021/acs.energyfuels.7b00691.

[44] D.-K. Nguyen, S. Verhelst, The temperature dependence of laminar burning velocities of methanol-syngas-air flames, in: FISITA 2016 World Automotive Congress, 2016. 
[49] A. Poran, M. Artoul, M. Sheintuch, L. Tartakovsky, Modeling internal

[51] J. Papavasiliou, G. Avgouropoulos, T. Ioannides, In situ combustion synthesis of structured $\mathrm{Cu}-\mathrm{Ce}-\mathrm{O}$ and $\mathrm{Cu}-\mathrm{Mn}-\mathrm{O}$ catalysts for the production and purification of hydrogen, Applied Catalysis B: Environmental 66 (3-4) (2006) 168-174. doi:10.1016/j.apcatb.2006.03.011.

[52] M. V. Twigg, M. S. Spencer, Deactivation of copper metal catalysts for methanol decomposition, methanol steam reforming and methanol syn- 
thesis, Topics in Catalysis 22 (3-4) (2003) 191-203. doi:10.1023/A: 1023567718303 .

[53] CHEM1D,

$$
\text { A }
$$

one-dimensional

laminar

flame

code, Eindhoven University of Technology, URL https://www.tue.nl/en/university/departments/mechanicalengineering/research/research-groups/multiphase-and-reactive-flows/ourexpertise/research-topics/chem1d/.

${ }_{985}$ [54] J. Li, Z. Zhao, A. Kazakov, M. Chaos, F. L. Dryer, J. J. Scire, A comprehensive kinetic mechanism for $\mathrm{CO}, \mathrm{CH}_{2} \mathrm{O}$, and $\mathrm{CH}_{3} \mathrm{OH}$ combustion, International Journal of Chemical Kinetics 39 (3) (2007) 109-136. doi:10.1002/kin.20218.

[55] S. G. Davis, A. V. Joshi, H. Wang, F. Egolfopoulos, An optimized kinetic model of $\mathrm{H}_{2} / \mathrm{CO}$ combustion, Proceedings of the Combustion Institute 30 (1) (2005) 1283-1292. doi:10.1016/j.proci.2004.08.252.

[56] A. Omari, M. Shapiro, L. Tartakovsky, Laminar burning velocity of alcohol reforming products and effects of cellularity on flame propagation, SAE Technical Paper 2015-01-0775doi:10.4271/2015-01-0775.

[57] C. Olm, I. G. Zsély, T. Varga, H. J. Curran, T. Turányi, Comparison of the performance of several recent syngas combustion mechanisms, Combustion and Flame 162 (5) (2015) 1793-1812. doi:10.1016/j.combustflame. 2014.12 .001

[58] D.-K. Nguyen, S. Verhelst, Development of laminar burning velocity correlation for the simulation of methanol fueled SI engines operated with

口 onboard fuel reformer, SAE Technical Paper 2017-01-0539doi:10.4271/ 2017-01-0539.

[59] J. Vancoillie, S. Verhelst, J. Demuynck, Laminar burning velocity correlations for methanol-air and ethanol-air mixtures valid at SI engine conditions, SAE Technical Paper 2011-01-0846doi:10.4271/2011-01-0846 
[60] C. Olikara, G. L. Borman, A computer program for calculating properties of equilibrium combustion products with some applications to IC engines, SAE Technical Paper 750468doi:10.4271/750468

[61] P. Schiffmann, D. L. Reuss, V. Sick, Empirical investigation of spark-ignited flame-initiation cycle-to-cycle variability in a homogeneous charge reciprocating engine, International Journal of Engine Research 19 (5) (2018) 491-508. doi:10.1177/1468087417720558.

[62] V. K. Chakravarthy, C. S. Daw, J. A. Pihl, J. C. Conklin, Study of the Theoretical Potential of Thermochemical Exhaust Heat Recuperation for Internal Combustion Engines, Energy \& Fuels 24 (3) (2010) 1529-1537. doi:10.1021/ef901113b.

[63] L. F. Brown, A comparative study of fuels for on-board hydrogen production for fuel-cell-powered automobiles, International Journal of Hydrogen Energy 26 (4) (2001) 381-397. doi:10.1016/S0360-3199(00) 00092-6.

[64] J. Li, A. Kazakov, M. Chaos, F. Dryer, Chemical kinetics of ethanol oxidation, in: 5th US combustion meeting, 2007, pp. 25-28.

[65] L. Sileghem, V. Alekseev, J. Vancoillie, E. Nilsson, S. Verhelst, A. Konnov, Laminar burning velocities of primary reference fuels and simple alcohols, Fuel 115 (2014) 32 - 40. doi:10.1016/j.fuel.2013.07.004.

[66] K. Morganti, Y. Viollet, R. Head, G. Kalghatgi, M. Al-Abdullah, A. Alzubail, Maximizing the benefits of high octane fuels in spark-ignition engines, Fuel 207 (2017) 470-487. doi:10.1016/j.fuel.2017.06.066. 